OPEN ACCESS

Edited by:

Leandro J. Carreno,

University of Chile, Chile

Reviewed by:

Christian Hundhausen, Heinrich Heine University of

Düsseldorf, Germany

Christoph Konradt,

Purdue University, United States

Randy Longman,

Cornell University, United States

*Correspondence:

Alexei V. Tumanov

tumanov@uthscsa.edu

Specialty section:

This article was submitted to Microbes and Innate Immunity,

a section of the journal

Frontiers in Cellular and

Infection Microbiology

Received: 14 September 2021 Accepted: 03 November 2021 Published: 06 December 2021

Citation:

Korchagina AA, Koroleva $E$ and Tumanov AV (2021) Innate

Lymphoid Cells in Response to Intracellular Pathogens: Protection Versus Immunopathology. Front. Cell. Infect. Microbiol. 11:775554. doi: 10.3389/fcimb.2021.775554

\section{Innate Lymphoid Cells in Response to Intracellular Pathogens: Protection Versus Immunopathology}

\author{
Anna A. Korchagina, Ekaterina Koroleva and Alexei V. Tumanov* \\ Department of Microbiology, Immunology and Molecular Genetics, University of Texas Health Science Center at San Antonio, \\ San Antonio, TX, United States
}

Innate lymphoid cells (ILCS) are a heterogeneous group of cytokine-producing lymphocytes which are predominantly located at mucosal barrier surfaces, such as skin, lungs, and gastrointestinal tract. ILCs contribute to tissue homeostasis, regulate microbiota-derived signals, and protect against mucosal pathogens. ILCs are classified into five major groups by their developmental origin and distinct cytokine production. A recently emerged intriguing feature of ILCs is their ability to alter their phenotype and function in response to changing local environmental cues such as pathogen invasion. Once the pathogen crosses host barriers, ILCs quickly activate cytokine production to limit the spread of the pathogen. However, the dysregulated ILC responses can lead to tissue inflammation and damage. Furthermore, the interplay between ILCs and other immune cell types shapes the outcome of the immune response. Recent studies highlighted the important role of ILCs for host defense against intracellular pathogens. Here, we review recent advances in understanding the mechanisms controlling protective and pathogenic ILC responses to intracellular pathogens. This knowledge can help develop new ILC-targeted strategies to control infectious diseases and immunopathology.

Keywords: innate lymphoid cells, intracellular pathogens, ILC plasticity, IFN $\gamma$, immunopathology

\section{INTRODUCTION}

Numerous human infectious diseases are caused by intracellular pathogens that include bacteria, fungi, parasites, and viruses. In the majority of cases, infection is controlled by the host immune system which leads to the clearance of the pathogen in a relatively short period of time. However, infections with some intracellular pathogens result in long lasting course of disease accompanied by severe chronic inflammation with high morbidity and mortality, especially in individuals with compromised immune

\footnotetext{
Abbreviations: ILCs, innate lymphoid cells; NK cells, natural killer cells; Th1, type $1 \mathrm{~T}$ helper cells; Th0, naïve T cells; IFN $\gamma$, interferon gamma; NCR, natural cytotoxicity receptor; T-bet, the interferon- $\gamma$ inducible T-box transcription factor; ROR $\gamma$, retinoic acid-related orphan receptor $\gamma t$ M1, M1 type macrophage; iNOS, inducible nitric oxide synthase; ROS, reactive oxygen species; APC, antigen-presenting cell; MHC, major histocompatibility complex; $\mathrm{LT} \alpha_{1} \mathrm{LT} \beta_{2}$, heterotrimeric lymphotoxin complex; CCL2, C-C motif ligand 2; CXCL10/11, C-X-C motif chemokine ligand 10/11; LT $\beta R$, lymphotoxin beta receptor; LT, lymphotoxin; LIGHT, lymphotoxin-like inducible protein that competes with glycoprotein D for herpes virus entry on $\underline{T}$ cells; HVEM, herpes virus entry mediator; MLN, mesenteric lymph node; IDO, indoleamine 2,3-dioxygenase; iBALT, inducible bronchus-associated lymphoid tissue; T. gondii, Toxoplasma gondii; C. jejuni, Campylobacter jejuni; Y. enterocolitica, Yersinia enterocolitica; Mtb, Mycobacterium tuberculosis; C. muridarum, Chlamydia muridarum; C. rodentium, Citrobacter rodentium.
} 
system (Thakur et al., 2019). Traditionally, intracellular pathogens are categorized into two groups based on their dependence on host cells: facultative and obligate intracellular pathogens (Leon-Sicairos et al., 2015; Casadevall and Fang, 2020). Facultative intracellular pathogens are capable of surviving and replicating both inside and outside the cell, whereas obligate intracellular pathogens entirely rely on intracellular resources of the host cell to reproduce and grow (Leon-Sicairos et al., 2015; Casadevall and Fang, 2020). Most pathogens invade the host through the barrier and mucosal surfaces such as skin, respiratory, reproductive, and digestive tracts. Pathogen invasion leads to acute inflammation, which is characterized by immediate and non-specific production of cytokines and chemokines, directing the innate lymphoid cells (ILCs) to the site of inflammation. Controlled acute immune response usually results in pathogen elimination and restoration of tissue homeostasis. However, dysregulated immune response that persists for a long time without resolution can lead to tissue damage and chronic inflammation.

Interferon gamma (IFN $\gamma$ ) is known as one of the key cytokines which modulates the innate and adaptive immune responses against intracellular pathogens (Schroder et al., 2004; Kak et al., 2018). Although the majority of studies have been focused on the role of IFN $\gamma$-producing $\mathrm{T}$ cells in host protection against intracellular pathogens, recent studies revealed the crucial role of ILCs in orchestrating type I immunity to pathogens. ILCs are an emerging heterogeneous family of tissue-resident innate lymphocytes that are critical for maintaining mucosal tissue homeostasis and promoting early immune response during inflammation (Vivier et al., 2018). Mirroring the subsets of $\mathrm{CD}^{+}$effector T cells, ILCs are classified into five major groups: Natural killer cells (NK), group 1 ILCs (ILC1), group 2 ILCs (ILC2), group 3 ILCs (ILC3) and lymphoid tissueinducer cells (LTi) (Vivier et al., 2018) (Figure 1). ILCs are enriched

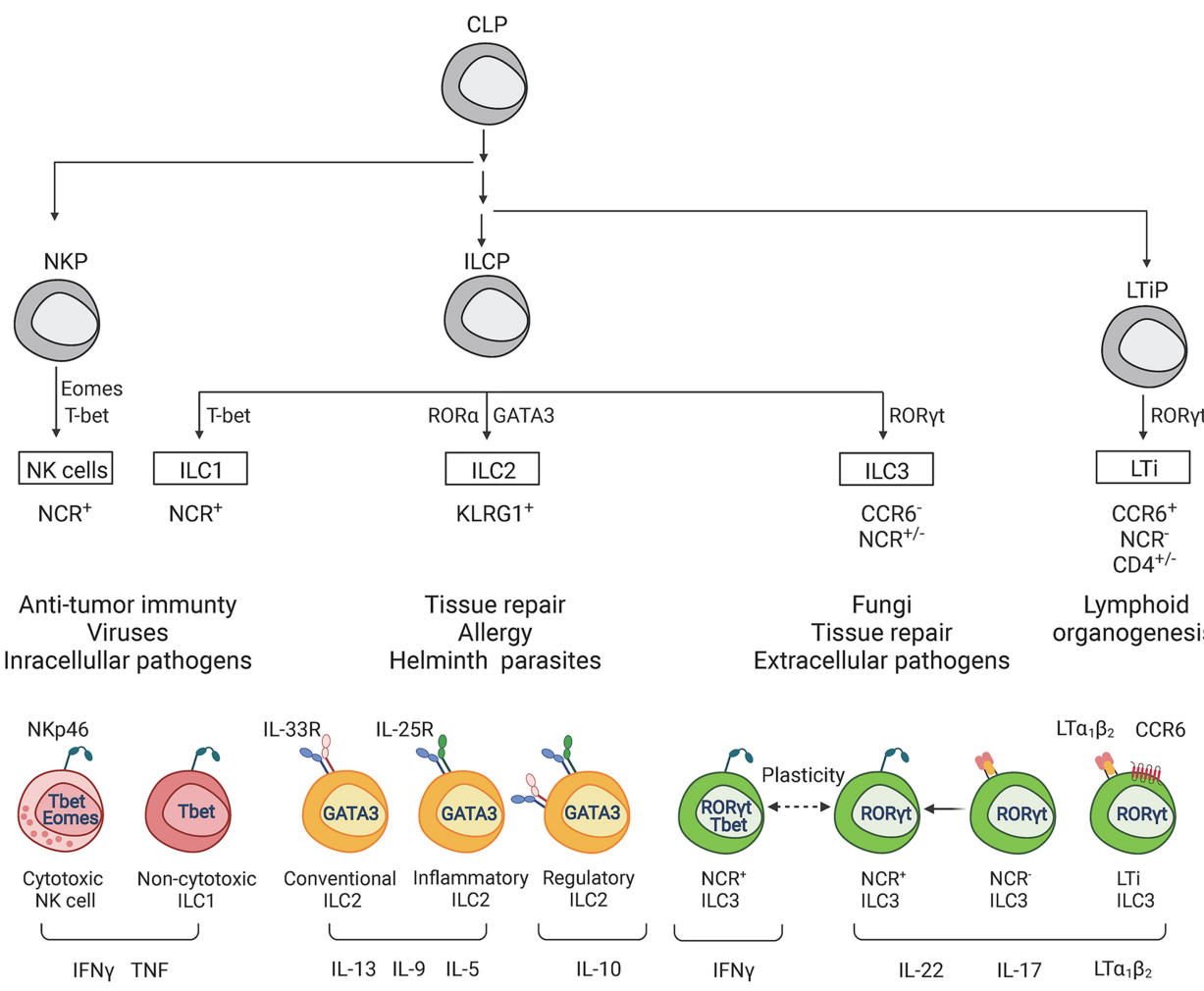

FIGURE 1 Classification of innate lymphoid cells. ILCs can be divided into 5 main subsets (NK cells, ILC1, ILC2, ILC3 and LTi cells) based on the differentiation stages, signature transcriptional factors and function. All ILCs develop from common lymphoid progenitor (CLP), which gives rise to three main subtypes of ILCs precursors: NK cell precursor (NKP), innate lymphoid cell precursor (ILCP), and lymphoid tissue inducer progenitor (LTiP). NKPs give rise to NK cells, ILCPs to ILC1s, ILC2s, and ILC3s, LTiPs - to LTi cells. Development and function of each ILC subset depends on corresponding specific transcriptional factors. Main signature transcriptional factors are illustrated: Eomes (Eomesodermin), T-bet (T-box transcriptional factor), GATA3 (GATA binding protein 3), ROR $\gamma$ (RAR-related orphan receptor $\gamma$ t). Additional transcriptional factors participate in subsequent cell lineage differentiation: ID2, PLZF, TCF7, TOX, NFIL3, ROR $\alpha$, AHR, RUNX3, BCL11b and others (not shown). IL-15 is required for the development of NK cells and ILC1s, whereas IL-7 and IL-2 are required for the development of ILC2s and ILC3s. NK cells and ILC1s contribute to defense against intracellular bacteria by producing TNF and IFN $\gamma$. NK cells are the cytotoxic ILCs which require Eomes for their development. Both ILC1s and NK cells express T-bet and produce IFN $\gamma$ as a signature cytokine. ILC2 subsets contribute to immunity against large extracellular parasites and allergens by producing type 2 cytokines IL-13, IL-9, IL-10, IL-5. ILC2s are defined by high KLRG1 and GATA3 expression. Inflammatory and conventional ILC2s are classified based on response to IL-25 and IL-33 cytokines, respectively. ILC3s and LTis require ROR expression for their development. ILC3s contribute to immune response against extracellular pathogens. ILC3 subsets include natural Cytotoxicity receptor (NCR) ${ }^{+}$ILC3s, NCR ILC3s, and NCR ${ }^{+}$ILC1s derived from NCR'ILC3s due to plasticity (ex-ILC3s). IL-22, IL-17 and membrane lymphotoxin LT $\alpha_{1}$ LT $\beta_{2}$ are key cytokines produced by ILC3s. In contrast to ILC3s, LTis express CCR6 ${ }^{+}$and CD4 but lack NCR. LTi contribute to the development of lymph nodes and gut-associated lymphoid tissues by expressing membrane lymphotoxin $L T \alpha_{1} L T \beta_{2}$ complex. 
at mucosal surfaces, where they are located in close proximity to epithelial surfaces and rapidly initiate cytokine production in response to tissue damage and invading pathogens. The role of ILCs in regulation of protective responses to pathogens has been discussed in recent reviews (Beck et al., 2020; Seo et al., 2020). However, accumulating evidence suggests that dysregulated ILC responses can result in tissue damage and immunopathology (Buonocore et al., 2010; Vonarbourg et al., 2010; Bernink et al., 2013; Klose et al., 2013; Munoz et al., 2015; Muraoka et al., 2021). Additionally, dysregulation of ILCs can lead to chronic inflammation and autoimmunity, promoting diseases such as psoriasis (Villanova et al., 2014; Ward and Umetsu, 2014; Bielecki et al., 2021), atopic dermatitis (Brüggen et al., 2016), asthma (Cayrol and Girard, 2019) and inflammatory bowel disease (IBD) (Bernink et al., 2013; Bernink et al., 2015; Forkel and Mjosberg, 2016; Forkel et al., 2019). The mechanisms controlling the balance between protective and pathogenic responses mediated by ILCs remain poorly understood. In this review, we will focus on recent updates in ILC-dependent mechanisms that control protective and pathogenic responses induced by intracellular pathogens.

\section{ILC SUBSETS IN HOMEOSTATIC CONDITIONS AND DISEASE}

NK cells and ILC1s contribute to immune response against intracellular pathogens by producing TNF and IFN $\gamma$ (Vivier et al., 2018; Seo et al., 2020). NK cells were initially included in the ILC1 group because of the similarities between NK cells and ILC1s. Thus, both populations express transcription factor T-bet and produce IFN $\gamma$ in response to IL-12 stimulation. IL-15 is required for differentiation, homeostasis, and function of NK cells and ILC1s (Daussy et al., 2014). In addition to IFN $\gamma$, both NK cells and ILC1s can rapidly produce TNF in response to intracellular pathogens (Vivier et al., 2018; Seo et al., 2020). Similarly to NK cells, ILC1s express natural cytotoxicity receptors (NCRs) including NK1.1 and NKp46 (Fuchs et al., 2013). However, in contrast to NK cells, ILC1s require T-bet for their development, whereas NK cells need T-bet only for maturation but require Eomes for their differentiation (Gordon et al., 2012; Daussy et al., 2014). Moreover, NK cells and ILC1s arise from the different subpopulations of common lymphoid progenitors (CLPs): NK cells develop from NK cell precursors (NKP), whereas ILC1, 2, and 3 develop from innate lymphoid cell precursors (ILCP) (Klose et al., 2014; Vivier et al., 2018) (Figure 1). Therefore, based on the emerging functional, transcriptional, and epigenetic analyses of NK cells and ILC1s, they are now considered as distinct lineages within the ILC family.

ILC2s are essential for control of helminth infections (Neill et al., 2010; Price et al., 2010) and tissue repair (Palm et al., 2012) and are involved in pathogenesis of asthma and allergy (Ho et al., 2015; Silver et al., 2016; Xiao et al., 2021) by secretion of type 2 cytokines IL-5, IL-9 and IL-13. Moreover, IL-2 and IL-7 are required for both ILC2s and ILC3s development and function (Vivier et al., 2018). ILC2s require the transcription factors
GATA3 and ROR $\alpha$ for their development and maintenance (Mjosberg et al., 2012; Wong et al., 2012; Walker and McKenzie, 2013; Ferreira et al., 2021). ILC2s are classified into two subtypes based on their response to distinct cytokines. Inflammatory ILC2 (iILC2s) respond to IL-25 and contribute to helminth expulsion, whereas natural ILC2s (nILC2s) are mainly present at a steady state and respond to IL-33 (Huang et al., 2015; Huang and Paul, 2016). Recently, a new population of ILC2s was identified in the lungs, which can produce IL-10 in response to IL-33 (Seehus et al., 2017; Golebski et al., 2021; Howard et al., 2021). IL-10-producing ILC2s are characterized by decreased expression of proinflammatory genes and have reduced ability to recruit eosinophils to the lungs (Seehus et al., 2017). Moreover, these cells have a distinct transcriptional profile which separates them from recently identified IL-10 producing ILCs in the gut named ILCregs (Seehus et al., 2017). Recent studies showed that ILC2s can upregulate the expression of T-bet and acquire ILC1-like effector program in inflamed lung tissue of patients with chronic obstructive pulmonary disease (COPD) as well as in inflamed nasal tissue (Bal et al., 2016; Silver et al., 2016). However, IL-10-producing ILC2s fail to acquire T-bet and IFN $\gamma$ expression upon IL-33-mediated activation, suggesting that they are distinct from IFN $\gamma$-producing ILC1-like cells (Seehus et al., 2017). Additionally, a recent study demonstrated that human ILC2s produce IL-10 to maintain epithelial integrity upon allergen exposure and can inhibit Th2 responses in an IL-10-dependent manner (Golebski et al., 2021). Although ILC2s have been extensively studied in the lungs, limited data is available on the role of ILC2s in the intestine. So far, the protective role of ILC2s activated by IL-33 was demonstrated in DSS colitis model (You et al., 2020; Ngo Thi Phuong et al., 2021) in which activated ILC2s produced IL-13 thereby inducing goblet cell expansion and intestinal barrier repair (Klose et al., 2017). Additionally, IL-13 from ILC2s may promote M2 macrophage polarization leading to reduced intestinal inflammation (You et al., 2020). However, the role of ILC2s in intestinal inflammation in humans remains largely unexplored. An increased ILC2 numbers have been reported in IBD patients (Lim et al., 2016; Forkel et al., 2019). Recent study revealed an increase of SLAMF1 ${ }^{+}$(Signaling Lymphocytic Activation Molecule Family Member 1) ILC2s in the intestine of Crohn's disease patients compared to healthy individuals (Mazzurana et al., 2021). Moreover, the frequency of SLAMF $1^{+}$ILC2s negatively correlated with disease progression (Mazzurana et al., 2021). Another study found that SLAMF1 expression was associated with IL-13 expression by ILC2s in the lung (Mazzurana et al., 2021). However, IL-13-producing ILC2s from intestinal samples of Crohn's disease patients can also produce IFN $\gamma$ (Lim et al., 2016), which could contribute to intestinal pathology. Thus, the role of ILC2s in intestinal inflammation needs to be further clarified.

Several studies showed that ILC2s activation can be controlled by neuroregulators such as neuromedin U (NMU) (Nagashima et al., 2019; Pu et al., 2021). ILC2s are located in close proximity to cholinergic neurons that secrete NMU in the intestine and lungs (Cardoso et al., 2017; Klose et al., 2017; 
Wallrapp et al., 2017). ILC2s express high levels of NMU receptor, Nmur1, which is required to induce type 2 cytokines for protection against worm infection in the lungs and intestine (Cardoso et al., 2017; Wallrapp et al., 2017). Interestingly, NMU triggers immediate production of IL-5, IL-13 and IL-9 by ILC2s, whereas IL-33 and IL-25 stimulation delays activation of ILC2s, suggesting rapid neuronal-dependent activation of immune mechanisms in response to changing environmental cues (Cardoso et al., 2017; Klose et al., 2017). Additionally, ILC2s activated by NMU produce IL- 9 , which in turn induces expansion of IL-17A-producing $\gamma \delta \mathrm{T}$ cells in the lung during sepsis (Chen et al., 2021). NMU regulates ILC2 protective responses through induction of IL-10, which inhibits IL-33mediated eosinophil recruitment to the lungs (Bando et al., 2020). Another neuropeptide, Calcitonin gene-related peptide (CGRP), suppresses IL-33- and NMU-activated ILC2s proliferation and IL-13 production but promotes IL-5 secretion during helminth infection (Vivier et al., 2009; Nagashima et al., 2019). These studies demonstrate the complexity of neuropeptide- ILC2s interactions, which are context- and tissue-dependent.

Recent findings indicate that ILC2s can migrate from the intestine to the lungs in response to helminth infection or cytokine stimulation (Huang et al., 2018; Pu et al., 2021). Moreover, gut microbiome can influence the immune responses locally or systemically. Stomach microbiota induces IL-7 and IL-33 production, leading to expansion of ILC2s. In turn, ILC2s produce IL-5 for IgA-mediated control of Helicobacter pylori in the stomach (Satoh-Takayama et al., 2020). Gut microbiota can also contribute to asthma development in infants via regulation of ILC2s effector function (Chua et al., 2018). Intestinal dysbiosis activates colon epithelial cells to secrete IL-33, IL-25 and TSLP, leading to IL-13 production by ILC2s to induce migration of dendritic cells and differentiation of Th2 cells (Chua et al., 2018). IL-5 produced by ILC2s and Th2 cells recruits eosinophils to colon and lungs, thereby promoting asthma development (Chua et al., 2018). While the detailed mechanism of microbiota-mediated regulation of ILC2s migration from the gut to the lungs remains to be determined, it has been recently demonstrated that IL-33/CXCL16 axis regulates migration of nILC2 to the lungs, whereas IL-25/CCL25 axis facilitates migration of iILC2s to the intestine during infection ( $\mathrm{Pu}$ et al., 2021).

ILC3s predominantly respond to extracellular pathogens and fungi by producing type 3 cytokines (IL-22, IL-17) and lymphotoxin (LT) (Colonna, 2009; Vivier et al., 2009; Tumanov et al., 2011; Kruglov et al., 2013). The development and differentiation of ILC3s is dependent on the constitutive expression of transcription factor retinoic acid-related orphan receptor $\gamma \mathrm{t}(\mathrm{ROR} \gamma \mathrm{t})$. Accordingly, ROR $\gamma \mathrm{t}$-deficient mice lack ILC3s (Cupedo et al., 2009; Sanos et al., 2009; Buonocore et al., 2010). ILC3s express the membrane complex $\mathrm{LT} \alpha_{1} \mathrm{LT} \beta_{2}$ and soluble $\mathrm{LT} \alpha_{3}$, which signal to lymphotoxin beta receptor (LT $\beta \mathrm{R}$ ) and TNFRs respectively (Tumanov et al., 2011; Kruglov et al., 2013). $\mathrm{LT} \alpha_{1} \mathrm{LT} \beta_{2}$ is not required for the development of ILC3s and LTi cells but contributes to IL-22 production by these cells via ILC3s interactions with dendritic cells and intestinal epithelial cells (Tumanov et al., 2011; Macho-Fernandez et al., 2015). Accordingly, mice lacking LT $\beta$ on ILC3s fail to produce IL-22 in response to the mucosal bacterial pathogen Citrobacter rodentium (C. rodentium) and succumb to infection (Wang et al., 2010; Tumanov et al., 2011). LT expression by ILC3s also controls the development of NK cells via LT $\beta \mathrm{R}$ signaling on stromal cells (Kim et al., 2014; Shou et al., 2021). Additionally, aryl hydrocarbon receptor (Ahr) controls the maintenance and postnatal expansion of ILC3s (Kiss and Diefenbach, 2012; Klose et al., 2013). ILC3s are divided into at least two subsets based on expression of natural cytotoxicity receptor (NCR): $\mathrm{NCR}^{+} \mathrm{ILC} 3 \mathrm{~s}$ and $\mathrm{NCR}^{-}$ILC3s. $\mathrm{NCR}^{+} \mathrm{ILC} 3 \mathrm{~s}$ require $\mathrm{T}$-bet for their differentiation from NCR-ILC3 precursor cells (Cupedo et al., 2009; Sanos et al., 2009; Klose et al., 2013). Moreover, ILC3s can undergo conversion toward ILC1s (Klose et al., 2013; Bernink et al., 2015). The plasticity between ILC populations is controlled by distinct cytokines and transcription factors (Bal et al., 2020). For example, NCR ${ }^{-1 L C} 3$ to $\mathrm{NCR}^{+} \mathrm{ILC} 1$ plasticity is controlled by the balance of ROR $\gamma t$ and T-bet (Vonarbourg et al., 2010; Bal et al., 2020).

LTi cells are critical for the development of lymph nodes and Peyer's patches (PP) during embryogenesis (Mebius et al., 1997; Eberl et al., 2004). Expression of surface $\mathrm{LT} \alpha_{1} \mathrm{LT} \beta_{2}$ complex on LTi cells is critical for the development of lymph nodes, PPs, isolated lymphoid follicles, and cryptopatches in the intestine via interactions with LT $\beta$ R on lymphoid tissue organizer cells (BarEphraïm and Mebius, 2016; Onder and Ludewig, 2018). Accordingly, mice lacking surface lymphotoxin on LTi cells fail to develop lymph nodes and gut-associated lymphoid tissues (Kruglov et al., 2013). Fetal LTi cells are replaced by bonemarrow derived hematopoietic stem cells during adulthood (Simic et al., 2020; van de Pavert, 2021). However, the role of LTi cells in mucosal immune response in adulthood remains poorly understood. CCR ${ }^{+}$LTi-like cells are the adult counterpart of LTi cells, which participate in formation of isolated lymphoid follicles and cryptopatches via $\mathrm{LT} \alpha_{1} \mathrm{LT} \beta_{2}$ expression and remodeling of secondary lymphoid organs during infection and inflammation (Scandella et al., 2008; Colonna, 2009; Vivier et al., 2009). Additionally, ILC3s can regulate adaptive immune response directly by cell contactdependent interactions or indirectly via cytokine production (Hepworth et al., 2013; Hepworth et al., 2015; Castellanos et al., 2018; Rao et al., 2020).

ILC3s play a critical role in maintaining epithelial cells integrity during homeostasis and regulate rapid repair of epithelial barrier during inflammation (Vivier et al., 2018). ILC3s can be activated by multiple signals including cytokines, metabolites, microbial and neuronal signals (Chun et al., 2019). Myeloid-derived IL-23 and IL-1 $\beta$ activate ILC3s to produce IL-22 that targets epithelial and stromal cells to induce proliferation and release of antimicrobial peptides in response to C. rodentium (Tumanov et al., 2011; Qiu et al., 2012; Melo-Gonzalez and Hepworth, 2017). Glial cell-derived neurotrophic factor family ligands through neuroregulatory receptor RET promote IL-22 secretion by ILC3s (Ibiza et al., 2016). ILC3s also secrete IL-22 in response to vasoactive intestinal peptide (VIP) 
produced by enteric neurons via VIPR2 (Seillet et al., 2020; Talbot et al., 2020). Recent studies revealed additional pathways which contribute to IL-22 production by ILC3s. Epithelial cell-derived IL$17 \mathrm{D}$ can induce IL-22 production by ILC3s through CD93 receptor during physiological and pathological conditions (Huang et al., 2021). Additionally, in response to bacterial metabolites such as short-chain fatty acids, free fatty acid receptor 2 (Ffar2) on colonic ILC3s contributes to IL-22 production (Chun et al., 2019). Besides the essential role of ILC3s in tissue repair, ILC3s can directly recognize neutrophil apoptosis during intestinal inflammation and after skin damage (Wang et al., 2021). Neutrophils, which undergo apoptosis during intestinal inflammation, release lysophosphatidylserine which can be sensed by ILC3s through GPR34 resulting in IL-22 production (Wang et al., 2021). Accordingly, mice lacking CD93, GPR34, or Ffar2 expression on ILC3s showed reduced IL-22 levels in the colon and increased bacterial burden following C. rodentium infection, although mice were able to survive the infection (Chun et al., 2019; Huang et al., 2021; Wang et al., 2021). Thus, multiple redundant pathways regulate IL-22 production by ILC3s to ensure robust IL-22 response to protect against mucosal pathogens and tissue damage.

Dynamic changes caused by chronic inflammation can result in phenotypical and functional changes in ILCs composition thereby contributing to disease pathology in patients with IBD (Geremia et al., 2011; Bernink et al., 2013; Bernink et al., 2015; Forkel et al., 2019). For example, number of ILC1s is increased whereas $\mathrm{NCR}^{+}$ILC3 subset is reduced in inflamed tissue of IBD patients (Takayama et al., 2010; Bernink et al., 2013; Forkel et al., 2019) and changes in ILCs composition correlated with disease severity (Forkel et al., 2019). Physiologically, ILC2s represent the major ILC subset in the skin, however during chronic inflammatory skin disease ILC2s undergo transition to ILC3s (Bielecki et al., 2021). Moreover, psoriasis patients treated with TNF blockers display reduced numbers of ILC3s suggesting their role in psoriasis pathogenesis (Villanova et al., 2014). In contrast to psoriasis, ILC2s are increased in patients with atopic dermatitis and ILC2s promote atopic dermatitis-like lesions in mouse models (Kim et al., 2013; Salimi et al., 2013; Imai et al., 2019). Thus, these studies suggest that the plasticity or disbalance between ILC subsets can contribute to pathogenesis of inflammatory diseases.

\section{PROTECTIVE AND PATHOGENIC EFFECTS OF IFN $\gamma$ PRODUCED BY ILCS IN RESPONSE TO INTRACELLULAR PATHOGENS}

IFN $\gamma$ can be synthesized by various immune cells such as NK cells and antigen-specific T cells (Okamura et al., 1998; Frucht et al., 2001). However, recent studies demonstrated that ILC1s and ILC3s can also secrete IFN $\gamma$ in response to activation (Vivier et al., 2018). Accumulating evidence suggests that IFN $\gamma$ produced by ILCs contributes to early host defense against pathogens, whereas IFN $\gamma$ produced by $\mathrm{T}$ cells is critical for adaptive immune response. IFN $\gamma$ secreted at early stages of infection enhances antigen presentation by antigen-presenting cells (APCs), such as macrophages and dendritic cells, by inducing MHC expression (Amaldi et al., 1989; Steimle et al., 1994; Xaus et al., 2000; Schroder et al., 2004). Additionally, APCs secrete IL-12, IL-15, and IL-18, which stimulate IFN $\gamma$ secretion at the infection site. Moreover, IL-12 can synergize with IL-18 to enhance IFN $\gamma$ production (Okamura et al., 1998; Tominaga et al., 2000; Frucht et al., 2001; Tait Wojno et al., 2019). IFN $\gamma$ production by ILCs is strictly regulated by lineage-defining and signaldependent transcriptional factors and cytokines (Mikami et al., 2018; Stabile et al., 2018). IL-12 binding to IL-12 receptor leads to STAT4 phosphorylation and induction of IFN $\gamma$ expression. Moreover, IFN $\gamma$ production by ILC1s and $\mathrm{NCR}^{+} \mathrm{ILC} 3 \mathrm{~s}$ is amplified by high levels of STAT4 expression induced by T-bet (Mikami et al., 2018; Yin et al., 2018). Additionally, coordinated expression of STAT4 and T-bet induces IFN $\gamma$ production by ILC3s after IL-23 activation (Mikami et al., 2018). Furthermore, Runx3 transcriptional factor modulates IL-12/STAT4 axis to promote secretion of IFN $\gamma$ by ILCs during bacterial infection (Yin et al., 2018). Bacterial lipopolysaccharides and other pathogen-associated molecular patterns directly induce IL-12 production by activated monocytes, macrophages, neutrophils and dendritic cells. In turn, IL-12 can further amplify IFN $\gamma$ by ILCs and T cells (Darwich et al., 2009; Tait Wojno et al., 2019) (Figure 2). Although both human and mouse ILCs express TLRs (Crellin et al., 2010; Maggi et al., 2017), it has yet to be demonstrated if activation of TLRs can directly induce IFN $\gamma$ production by ILCs. IFN $\gamma$ stimulates expression of CXCL9, CXCL10, and CXCL11 chemokines which promote CXCR3dependent recruitment of $\mathrm{T}$ cells and ILCs (Metzemaekers et al., 2017). In addition, IFN $\gamma$ activates macrophages, leading to increased phagocytosis as well as enhanced production of reactive nitric oxide (NO), and indoleamine 2,3-dioxygenase (IDO)-mediated tryptophan depletion (Decker et al., 2002; Popov et al., 2006) (Figure 2). NO is generated in immune cells from L-arginine and oxygen via inducible NO synthase (iNOS) (Bogdan, 2015). iNOS contributes to protection against intracellular pathogens such as Toxoplasma gondii (Dunay and Diefenbach, 2018), Listeria monocytogenes (Lu et al., 2015), Mycobacterium tuberculosis (Pahari et al., 2016; Braverman and Stanley, 2017) and Salmonella typhimurium (Yadav et al., 2020), as mice with inactivation of Nos 2 gene are highly susceptible to these infections. The induction of IDO1 and consequent tryptophan degradation is an effective antimicrobial mechanism accelerated in response to IFN $\gamma$. For instance, IDO1 activation is an effective inhibitor of T. gondii replication (Dunay and Diefenbach, 2018), while IDO was shown to be not essential for control of M. tuberculosis (Blumenthal et al., 2012).

In contrast to protective effects of IFN $\gamma$ in response to intracellular pathogens, an increased or prolonged IFN $\gamma$ production results in tissue damage. For example, during the onset of inflammation, IFN $\gamma$ promotes epithelial cell proliferation through activation of AKT- $\beta$-catenin signaling pathway, which is potentiated by TNF (Nava et al., 2010). However, extended IFN $\gamma$ and AKT- $\beta$ catenin activation inhibits epithelial cell proliferation and induces 


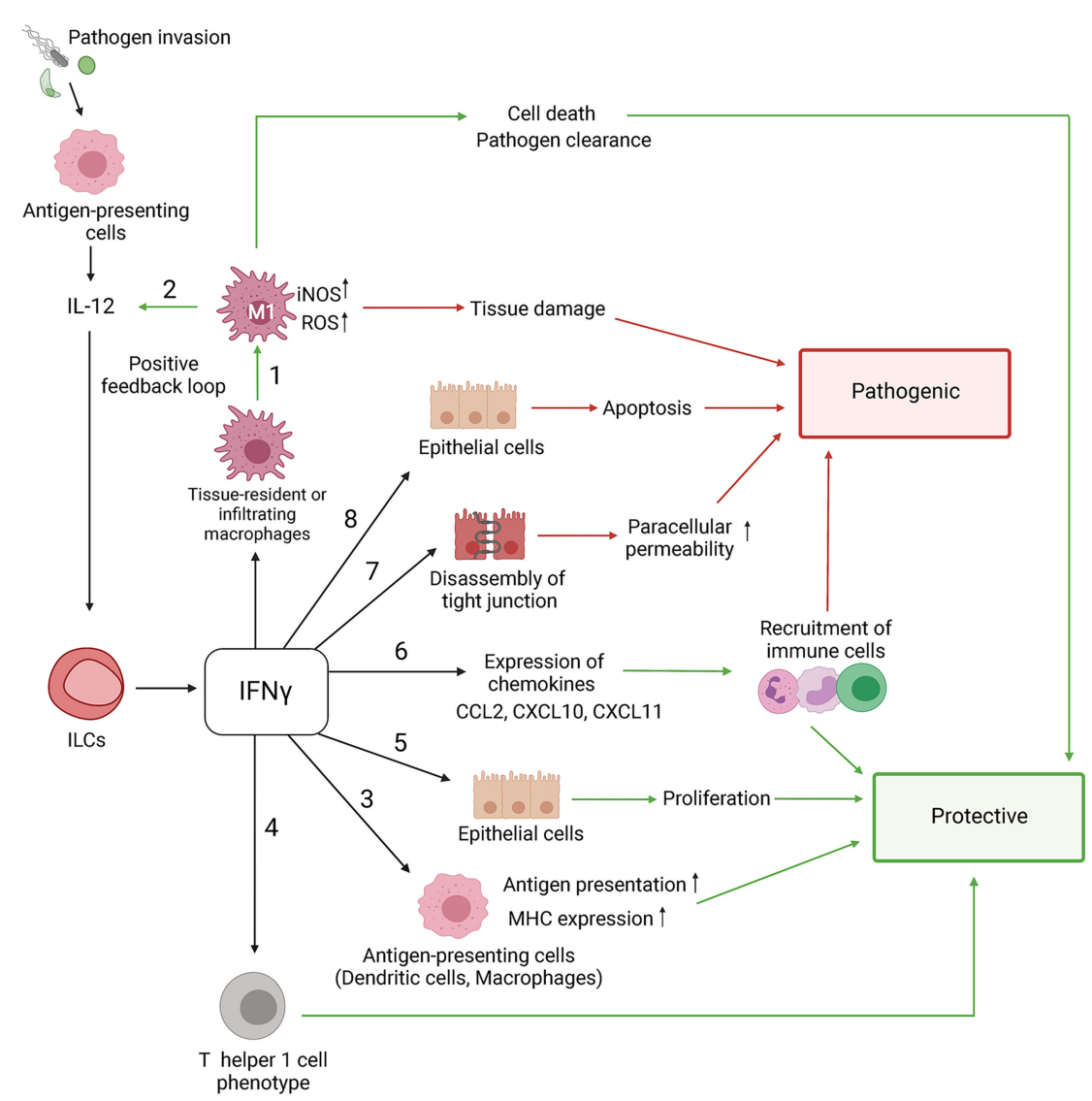

FIGURE 2 | Role of IFN $\gamma$ in protective and pathogenic responses to intracellular pathogens. The IFN $\gamma$-mediated effects are context-dependent and can contribute to both pathogen clearance and tissue damage. NK cells, ILCs and T cells are primary producers of IFNy under inflammatory conditions. 1) IFNy induces polarization of M1 macrophages that produce high levels of reactive oxygen species (ROS) and nitric oxide (NO) which results in death of pathogen-infected cells and tissue damage. 2)

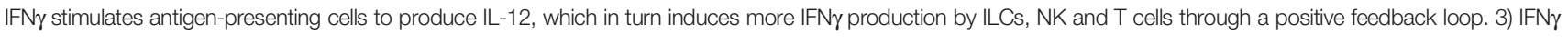
induces $\mathrm{MHC}$ I and $\mathrm{MHC}$ II expression which promotes antigen presentation. IFN $\gamma$ stimulates: 4) Th1 T cell polarization, 5) proliferation of epithelial cells and 6) expression of inducible CXCL9, CXCL10, CXCL11 chemokines that recruit various immune cells via CXCR3. However, sustained activation of IFNy-R signaling can lead to chronic inflammation and tissue damage. 7) IFNy regulates epithelial barrier permeability by altering intercellular tight junctions leading to increased permeability to intestinal bacteria and pathogens. 8) IFN $\gamma$ can exacerbate intestinal inflammation through inhibition of epithelial cell proliferation and promotion of apoptosis. Green/red arrows indicate protective/pathogenic responses.

apoptosis by activating Wnt inhibitor DKK1 (Nava et al., 2010). Increased IFN $\gamma$ production can also induce depletion of Paneth cells which produce cytotoxic antibacterial proteins and promote proliferation of Lgr5 $^{+}$intestinal stem cells (Eriguchi et al., 2018).

Epithelial barrier integrity is critical to restrict entrance of pathogens to the host and maintain tissue homeostasis. Intercellular tight junctions are critical for the maintenance of epithelial homeostasis (Chelakkot et al., 2018). Altered tight junction complexes result in increased epithelial cell permeability to pathogens and commensal bacteria, leading to altered barrier functions, production of inflammatory cytokines, and tissue damage (May et al., 1993; Zeissig et al., 2007; van der Gracht et al., 2016). Activation of IFN $\gamma$ signaling in epithelial cells can result in the weakening of intercellular tight junctions, thereby promoting permeability of the epithelial barrier. Indeed, biopsy samples from IBD patients demonstrated disrupted tight junctions and increased epithelial cell permeability (Schmitz et al., 1999;
Zeissig et al., 2007; Ahmad et al., 2017; Odenwald and Turner, 2017). In addition to impaired tight junctions, high rates of apoptosis in epithelial cells are also linked to IBD development (Zeissig et al., 2007; Chelakkot et al., 2018). Collectively, IFN $\gamma$ orchestrates numerous protective pathways to maintain tissue homeostasis and induce rapid immune response to reduce microbial burdens. However, excessive production of IFN $\gamma$ can lead to exacerbation of immune response, tissue damage, and chronic inflammation (Figure 2).

\section{ILCS IN IMMUNE RESPONSE TO INTRACELLULAR PATHOGENS}

\section{Toxoplasma gondii}

Toxoplasma gondii (T. gondii) is an obligate protozoan parasite that can infect all warm-blooded vertebrates and cause 
toxoplasmosis (Konradt et al., 2016; Dunay and Diefenbach, 2018). Infection with T. gondii may lead to parasite dissemination to the central nervous system and muscle tissue where T. gondii converts to bradyzoite-containing cysts that remain lifelong in the host (Konradt et al., 2016; Dunay and Diefenbach, 2018).

IFN $\gamma$ and IL-12 production is critical for protection against T. gondii, as IFN $\gamma^{-/-}$mice or IL $12 \mathrm{p} 35^{-/-}$mice succumb to infection (Suzuki et al., 1988; Scharton-Kersten et al., 1996; Lieberman et al., 2004). Activation of DCs, macrophages, and neutrophils in response to $T$. gondii results in the production of proinflammatory cytokines, including IL-12, which primes NK cells, ILCs, and T cells to secrete IFN $\gamma$ (Gazzinelli et al., 1994; Mashayekhi et al., 2011) (Figure 3). While NK cells are important for host resistance at early onset of $T$. gondiimediated disease, adaptive immunity mainly contributes to protection during chronic phase of infection (Denkers et al., 1993). NK cells produce IFN $\gamma$ which induces parasite destruction (Denkers et al., 1993; Yarovinsky, 2014). Insufficient IFN $\gamma$ production by NK cells during $T$. gondii infection is associated with reduced numbers of IFN $\gamma$-producing $\mathrm{CD} 4^{+}$and $\mathrm{CD} 8^{+} \mathrm{T}$ cells (Goldszmid et al., 2007; Ivanova et al., 2020). Additionally, IFN $\gamma$ produced by $\mathrm{NK}$ cells promotes differentiation of monocytes into inflammatory IL-12-producing DCs which contribute to protection (Goldszmid et al., 2012). Recent studies indicate that NK cells not only contribute to early protection against $T$. gondii but can also inhibit $\mathrm{CD}^{+} \mathrm{T}$ cells in chronic toxoplasmosis (Ivanova et al., 2020). Thus, it was shown that during chronic T. gondii infection, NK cells had reduced IFN $\gamma$ production and increased expression of CD107a a surface marker of NK cell activity (Ivanova et al., 2020). Depletion of these NK cells with anti-NK1.1 antibody rescued

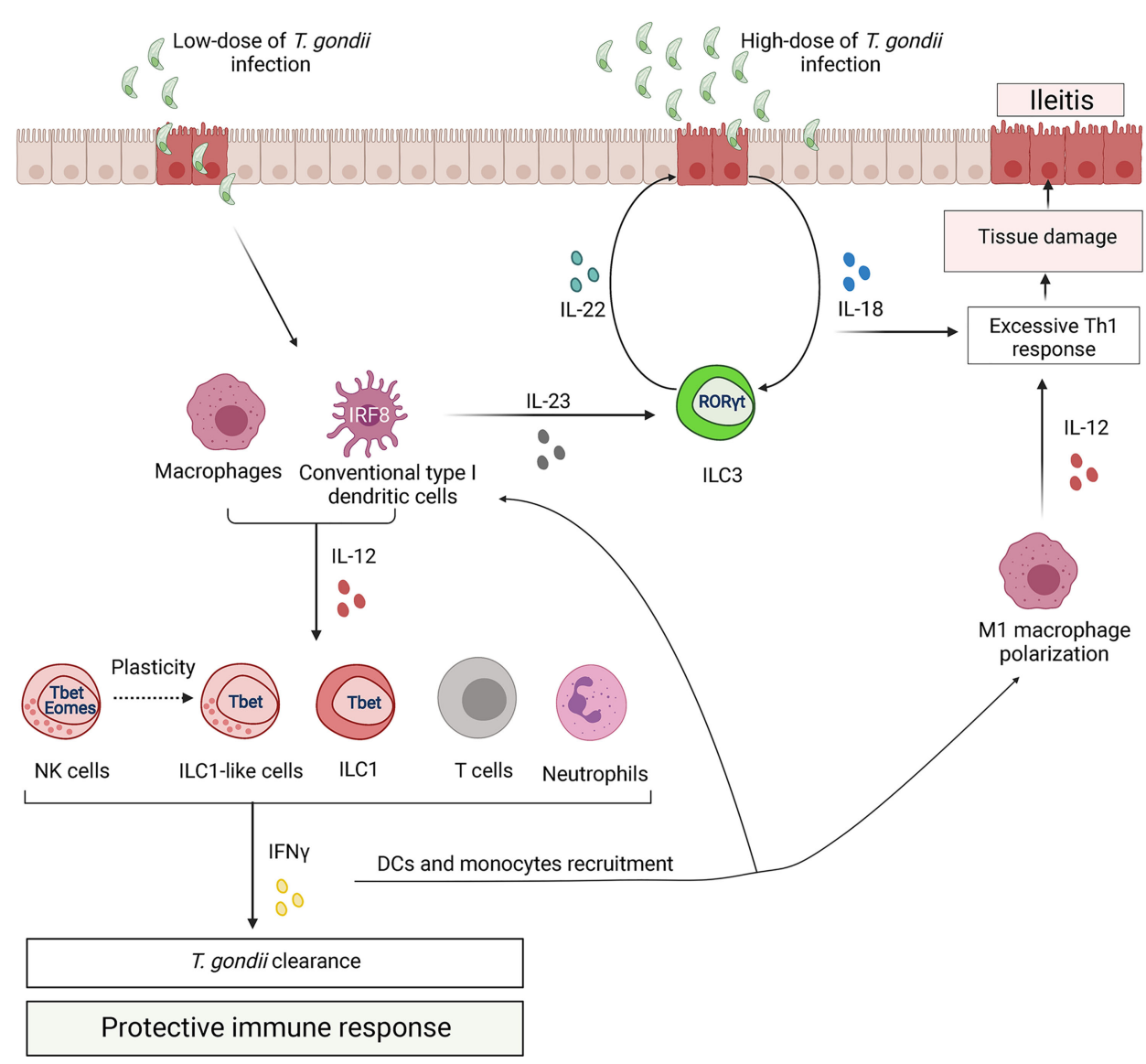

FIGURE 3 | ILCs regulate the immune response to Toxoplasma gondii. Control of parasite is associated with type 1 immune response. Upon infection, parasite infects ileum enterocytes. In response to T. gondii invasion, epithelial cells release cytokines (IL-8, CCL5 and CCL3), which activate antigen-presenting cells, particularly dendritic cells (DCs) and macrophages $(M \Phi)$. Additionally, T. gondii can directly activate DCs and M $\Phi$ through TLR11 and TLR12. Parasite recognition by

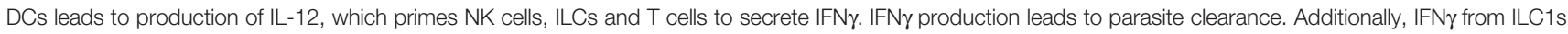
induces transcriptional factor IRF8 for differentiation of type I conventional DCs. T. gondii infection drives plasticity of NK cells to ILC1-like cells by downregulating expression of Eomes. In contrast, pathogenic IFN $\gamma$ promotes polarization of M1 macrophages. M1 macrophages produce more IL-12 leading to excessive activation of $\mathrm{CD}^{+} \mathrm{T}$ cells that can lead to tissue damage. Moreover, upon T. gondii infection intestinal epithelial cells produce IL-18 that enhances IFN $\gamma$ induction. Additionally, DCs-derived IL-23 synergizes with IL-18 to induce IL-22 production by ILC3s. ILC3-driven IL-22 enhances production of IL-18 by epithelial cells resulting in amplification of pathogenic positive feedback loop that exacerbates Th1-induced immune response. 
chronic T. gondii infected mice from $\mathrm{CD}^{+} \mathrm{T}$ cell exhaustiondependent death (Ivanova et al., 2020). NK cell depletion reduced $\mathrm{CD}^{+} \mathrm{T}$ cell apoptosis, indicating that $\mathrm{NK}$ cells can contribute to $\mathrm{CD} 8^{+} \mathrm{T}$ cell exhaustion by promoting apoptosis (Ivanova et al., 2020). However, the molecular mechanisms by which NK cells inhibit $\mathrm{CD} 8^{+} \mathrm{T}$ cells remain unclear.

Recent studies demonstrated that along with NK cells, ILC1s also contribute to host defense against T. gondii and to parasite clearance (Klose et al., 2014; Lopez-Yglesias et al., 2021). Genetic deletion of T-bet resulted in profound loss of IFN $\gamma$ production due to a deficiency of ILC1s, despite unaffected NK cell numbers in the small intestine during T. gondii infection (Klose et al., 2014). Furthermore, these studies suggest that ILC1s are a primary cellular source of IFN $\gamma$ in the small intestine rather than NK cells or NKp $46^{+} \mathrm{NK} 1.1^{+}$ILC3s.

Inflammatory monocytes directly limit early $T$. gondii replication, whereas DCs are the major cellular source of IL-12, which is produced upon activation of pattern recognition receptors by parasite (Dunay et al., 2008). More recently, it became evident that ILC1s and NK cells promote the recruitment of inflammatory monocytes and DCs to protect against $T$. gondii (Goldszmid et al., 2012; Klose et al., 2014). Thus, T-bet-deficient mice lacking IFN $\gamma$-producing ILC1s showed significant reduction of $\mathrm{IRF}^{+}$inflammatory $\mathrm{DCs}$ and succumbed to T. gondii (Lopez-Yglesias et al., 2021). Moreover, infection with T. gondii promotes stromal cells to produce IL-33, which synergizes with IL-12 to amplify IFN $\gamma$ production by ILCs for protection (Clark et al., 2021). These data suggest that IL-12, IL-33 and IFN $\gamma$ mediate the crosstalk between ILC1s, stromal cells and DCs to protect against T. gondii infection.

T. gondii infection results in immunopathology associated with Th1 immune response (Yarovinsky, 2014; Dunay and Diefenbach, 2018) (Figure 3). It is important to note that the parasite dose, strain, and infection route can influence the outcome of infection (Dunay and Diefenbach, 2018). Thus, infections with low parasite cyst numbers ( $<20$ cysts) or with less virulent strains lead to protective Th1 immune response, whereas oral infections with higher parasite doses cause extensive production of proinflammatory cytokines, leading to exacerbation of ileitis induced by T. gondii (Munoz et al., 2011). These differences may explain contradictory reports on the role of IL-22 and IL-18 in T. gondii-mediated intestinal pathology (Munoz et al., 2009; Wilson et al., 2010; Munoz et al., 2015; Couturier-Maillard et al., 2018). Thus, sustained IL-22 and IL-18 production promoted intestinal inflammation in the high dose oral infection model, as IL- $22^{-/-}$and IL- $18^{-/-}$mice exhibited significantly less infection-induced ileitis (Munoz et al., 2015). However, there was no difference in tissue pathology and the number of IFN $\gamma^{+}$cells between WT and IL- $22^{-/-}$mice following low-dose of intraperitoneal infection with T. gondii (Wilson et al., 2010). IL-18 is known to protect against intracellular pathogens by amplifying IFN $\gamma$ production together with IL-12 (Frucht et al., 2001; Shtrichman and Samuel, 2001; Ivashkiv, 2018). However, excessive production of IL-18 by epithelial cells after infection with high dose of $T$. gondii contributes to intestinal pathology by inducing IFN $\gamma$ (Munoz et al., 2015). In contrast, IL-18 only slightly induces IFN $\gamma$ after low dose of infection (Vossenkamper et al., 2004; Munoz et al., 2009; Dunay and Diefenbach, 2018). Furthermore, after high dose of oral T. gondii infection, IL-18 synergizes with IL-23 for production of IL-22 (Munoz et al., 2015). DC-derived IL-23 induces IL-22 production by ILC3s. In turn, IL-22 induces IL-18 production by epithelial cells, thereby amplifying this pathogenic feedback loop (Wilson et al., 2010; Munoz et al., 2015; Victor et al., 2017) (Figure 3). Whether IL-22 can contribute to T. gondii- induced intestinal pathology independently from IL18 remains unclear.

Recently the first study describing infection-induced conversion of NK cells to ILC1-like cells was published in T. gondii infection model (Park et al., 2019). A previous study described the conversion of NK cells to ILC1-like cells within the tumor microenvironment (Gao et al., 2017), but, in contrast to tumor ILC1-like cells, T. gondii-induced ILC1-like cells were not tissue-resident but were able to circulate under inflammatory conditions (Park et al., 2019). Interestingly, ILC1-like cells were maintained after the infection was cleared, similarly to immune memory NK cells (Park et al., 2019). These findings suggest a previously underappreciated plasticity between NK cells and ILCs in immune response to $T$. gondii infection. The physiological significance of NK cell conversion to ILC1-like cells and the mechanisms that regulate this plasticity remain unknown and require further studies.

Although NK cells and ILC1s are required for IFN $\gamma$ dependent resistance against $T$. gondii in mouse models, the role of ILCs in human $T$. gondii infection and how findings in mice translate to human diseases remains to be determined. Mice as an intermediate $T$. gondii host potentially developed unique resistance mechanism which could be different from response in humans. Humanized animal models could provide a useful tool to address the role of human ILCs in response to parasite. Recent studies revealed that NK cells and ILC1s are present in the central nervous system (CNS) of mice (Romero-Suárez et al., 2019). Moreover, it has been shown that ILC1s can be recruited to CNS during experimental autoimmune encephalomyelitis and control the onset of neuroinflammation (Kwong et al., 2017). Since previous studies of ILCs were mostly focused on the periphery rather than CNS, it will be important to examine the role of ILCs in cerebral toxoplasmosis.

\section{Salmonella typhimurium}

Salmonella is a facultative intracellular bacterium which causes food-borne infectious gastroenteritis in humans called salmonellosis. The clinical disease in humans and animals is mainly caused by non-typhoidal Salmonella typhimurium and S. enteritidis, and usually is self-limiting. However, the clinical outcome of infection depends on the immunological status of the individual and serovar of bacteria. Salmonella infection can cause systemic disease that can be fatal, especially for immunocompromised individuals (Pham and McSorley, 2015). Although microfold cell ( $\mathrm{M}$ cells) and DCs in PPs are the main entry points for Salmonella, the bacterium can also use other routes for invasion, such as intestinal epithelium, and can 
disseminate and replicate in the spleen, liver, and phagocytic cells in bone marrow (Santos and Bäumler, 2004; Tahoun et al., 2012).

The innate immunity is essential for protection against Salmonella infection (Pham and McSorley, 2015). Recent data indicated that innate IFN $\gamma$ controls bacterial loads in the small intestine and systemic bacterial dissemination (Songhet et al., 2011; Kupz et al., 2013). Interestingly, NKp $46^{+} \mathrm{T}^{- \text {bet }^{+}}{ }^{+} \mathrm{LC}$ are the primary source of IFN $\gamma$, whereas only a small fraction of NK cells contributes to IFN $\gamma$ production (Klose et al., 2013). Cell fate-mapping experiments revealed that the majority of NKp46 ${ }^{+} \mathrm{T}$-bet ${ }^{+}$ILCs have a history of ROR $\gamma \mathrm{t}$ expression, suggesting that Salmonella infection can induce transdifferentiation of NKp46 ILC3s to IFN $\gamma$-producing ILC1s (Klose et al., 2013) (Figure 4). T-bet is required for conversion of $\mathrm{NKp} 46^{+} \mathrm{ROR} \gamma \mathrm{t}^{+}$ILCs from $\mathrm{NKp} 46^{-}$ ILC3s because T-bet-deficient mice $\left(T b \times 21^{--}\right)$lack NKp46 ${ }^{+} \mathrm{T}$ bet ${ }^{+} \mathrm{ROR} \gamma \mathrm{t}^{+}$ILCs and have fewer IFN $\gamma$-producing cells (Klose et al., 2013). IL-12 is required for IFN $\gamma$ production by ILCs after Salmonella infection (Klose et al., 2013). Although IL-12 $2^{-/}$ mice have normal numbers of $\mathrm{T}$-bet ${ }^{+} \mathrm{ROR} \gamma \mathrm{t}^{+}$ILCs, IFN $\gamma$ production in these mice is impaired (Klose et al., 2013). These findings indicate that IFN $\gamma$ production by NKp $46^{+} \mathrm{ROR} \gamma \mathrm{t}^{+}$ILC3s is dependent on IL-12 and T-bet. Subsequent studies demonstrated that IFN $\gamma$ production is dependent on the transcriptional complex of T-bet and Runx3 (Yin et al., 2018). Moreover, Salmonella infection induces Runx3 expression in ILC1s and NCR ${ }^{+}$ILC3s, but not in NK cells (Yin et al., 2018). Accordingly, genetic deletion of Runx3 in ILCs leads to high susceptibility of mice to Salmonella infection accompanied by decreased numbers of ILC1s and NCR ${ }^{+}$ILC3s (Yin et al., 2018). Although IFN $\gamma$ produced by $\mathrm{NKp} 46^{+} \mathrm{ROR} \gamma \mathrm{t}^{+}$ILCs contributes to bacterial clearance, it can also induce epithelial damage, as Tb $\times 21^{-/-}$and Ifngr $1^{-/-}$mice displayed reduced intestinal pathology 48h after infection (Klose et al., 2013). Additionally, IFN $\gamma$ produced by mucosal NK cells and $\mathrm{T}$ cells can delay the resolution of intestinal inflammation by inducing STAT1 activation and blocking of IL-22-RegIII $\beta$-mediated antimicrobial defense (Dolowschiak et al., 2016). These studies suggest that IFN $\gamma$-producing ILCs can also contribute to intestinal pathology during Salmonella infection (Figure 4).

NCR-ILC3s contribute to the protection against Salmonella by producing IL-22, which in turn induces production of RegIII $\beta$ and RegIII $\gamma$ antibacterial proteins by epithelial cells (Goto et al., 2014).

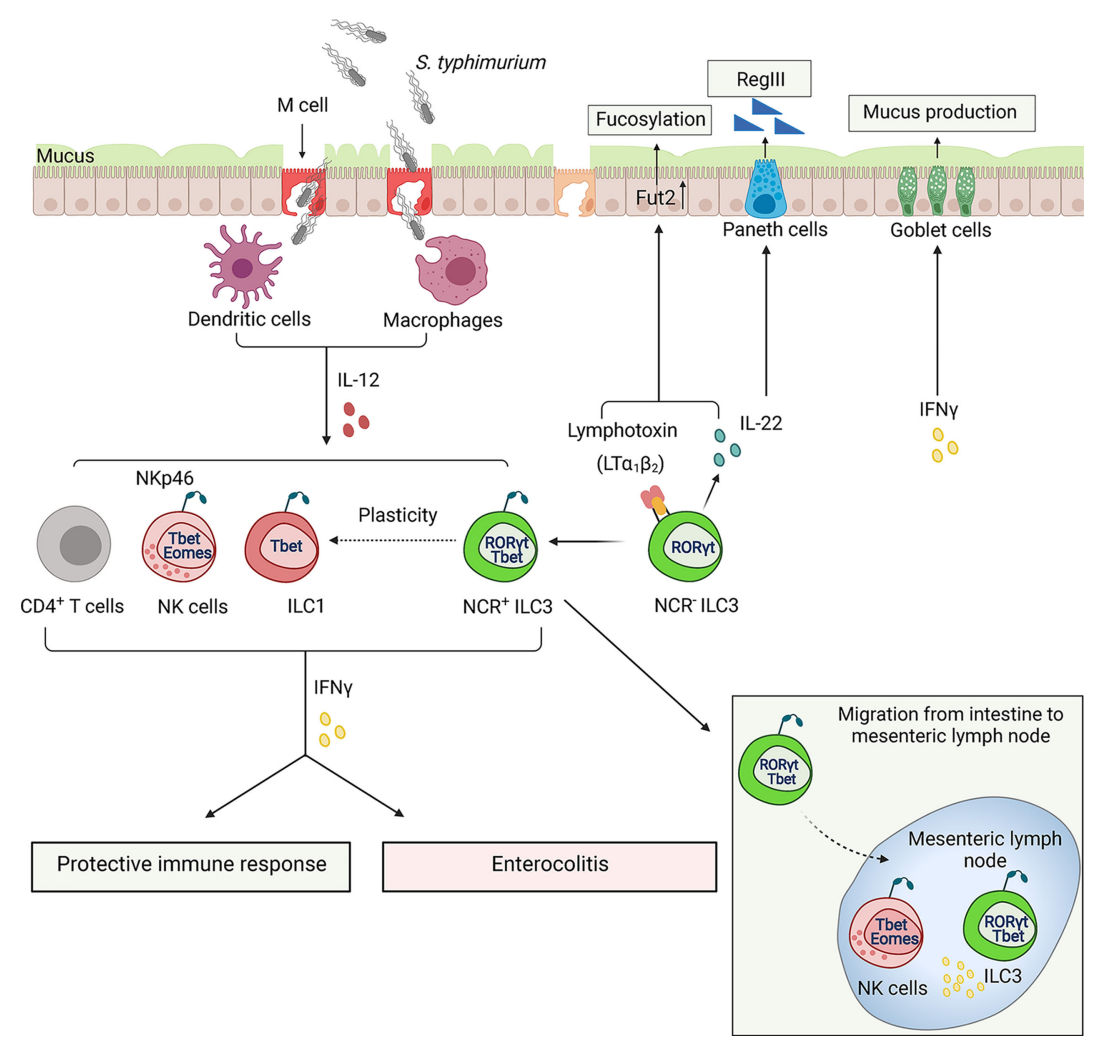

FIGURE 4 | ILCS regulate the immune response to Salmonella typhimurium. Salmonella use microfold cells (M cells), intestinal epithelial cells as an entry point to invade the host. Following ingestion, bacterium enters lamina propria, where it encounters dendritic cells (DCs) and macrophages (M $\Phi)$ which can spread bacteria to other tissues. Early control of S. typhimurium depends on the IFN $\gamma$ production from activated ILCs and NK cells. S. typhimurium induces transition of NCR ROR $\gamma t^{+} I L C 3$ s to $\mathrm{NCR}^{+} \mathrm{T}$-bet ${ }^{+} \mathrm{ILC}$ 1s via NCR ${ }^{+} \mathrm{T}$-bet ${ }^{+} \mathrm{ROR} \gamma \mathrm{t}^{+} \mathrm{ILC}$ s intermediates. IFN $\gamma$ plays a dual role in pathogenesis of Salmonella infection: it stimulates bacteria clearance and activates mucus production but also induces tissue damage resulting in exacerbation of enterocolitis. A minor population of T-bet ${ }^{+}$ROR $\gamma^{+}{ }^{+}$ILC3s can also migrate to mesenteric lymph node where ILC3s along with NK cells produce IFN $\gamma$. ILC3s can also contribute to protection against Salmonella via controlling fucosylation of epithelial cells by producing IL-22 and membrane $L T \alpha_{1} L T \beta_{2}$ lymphotoxin complex. 
Additionally, IL-22 stimulates expression of enzyme fucosyltransferase 2 (Fut2), which is required for epithelial fucosylation (Goto et al., 2014). Accordingly, ROR $\gamma \mathrm{t}^{-/-}$mice and Fut $2^{-/-}$mice display an increased susceptibility to Salmonella infection (Goto et al., 2014). Interestingly, $\mathrm{LT}^{-/-}$mice and mice treated with LT $\beta$ R-Ig inhibitor displayed reduced levels of Fut2 and fucosylation, suggesting that LT $\beta$ R signaling is required for epithelial fucosylation (Goto et al., 2014). It is currently unclear whether LT $\beta R$ signaling directly regulates Fut2-dependent fucosylation in epithelial cells or activates an indirect mechanism by inducing IL-22 production by ILC3s (Figure 4). LT expression by ILC3s is known to enhance IL-22 production by these cells via crosstalk with IL-23-producing mononuclear phagocytes and intestinal epithelial cells in response to extracellular bacterial pathogen C. rodentium or epithelial injury (Tumanov et al., 2011; Macho-Fernandez et al., 2015); however, it remains to be determined whether similar ILC3-LT-dependent mechanism is important for protection against Salmonella. A recent study demonstrated that LT expression by both ILC3s and B cells contributes to protection against Salmonella (Wroblewska et al., 2017). It was also found that $\mathrm{LT} \beta \mathrm{R}^{-/-}$mice display an impaired production of IFN $\gamma$ in response to chronic Salmonella infection (Wroblewska et al., 2017). Whether LT controls IFN $\gamma$ production by ILCs or adaptive immune cells remains to be determined.

Although ILCs are largely tissue-resident cells, there is emerging evidence that minor ILC populations can migrate to and within the tissues in response to the local environmental signals (Gasteiger et al., 2015; Kastele et al., 2021). A recent study showed that a small ILC population can migrate from the intestine to the mesenteric lymph node (MLN) in steady state and under inflammatory conditions (Kastele et al., 2021). Increased numbers of migratory ROR $\gamma \mathrm{t}^{+} \mathrm{T}$-bet ${ }^{+} \mathrm{ILCs}$ were found in the lymph nodes of Salmonella-infected mice, which served as an early source of IFN $\gamma$ along with NK cells (Kastele et al., 2021). However, the mechanism of ILC migration and its role in the regulation of adaptive immune response during inflammation remains poorly understood (Figure 4).

The major function of ILCs is to strengthen the epithelial barriers through various mechanisms. IFN $\gamma$ was shown to induce production of mucins by goblet cells. Mucins form the inner mucus layer to protect epithelial cells from bacterial invasion (Songhet et al., 2011; Klose et al., 2013). A previous study demonstrated that MUC2deficient mice showed an increased susceptibility to Salmonella infection (Zarepour et al., 2013). Fewer goblet cells filled with mucus were observed after infection with Salmonella (Klose et al., 2013). Moreover, Tbx $21^{-/-}$mice, which lack IFN $\gamma$-producing Nkp $46^{+}$ROR $\gamma t^{+}$ILCs, showed a decrease in mucus secretion. Experiments with depletion of ILCs revealed reduced IFN $\gamma$ and mucus secretion after Salmonella infection (Klose et al., 2013). These studies suggest that IFN $\gamma$-producing ILCs regulate goblet cells in response to Salmonella infection, although the detailed mechanism of ILC-dependent mucus secretion remains to be determined.

In summary, IFN $\gamma$-producing ILCs play a dual role in Salmonella infection. IFN $\gamma$ production by ILCs is critical for bacterial clearance in the gut and to restore the epithelial barrier. However, IFN $\gamma$ from ILCs can also induce mucus production and impair tight junction during infection, potentially leading to an additional tissue damage. Additional mechanistic studies are needed to dissect the role of ILC-produced IFN $\gamma$ in maintaining the integrity of epithelial barrier during Salmonella infection.

\section{Yersinia enterocolitica}

$Y$. enterocolitica and Y. pseudotuberculosis are food-borne enteropathogens which typically cause self-limiting infections of GI tract (Hering et al., 2011; Bancerz-Kisiel et al., 2018). However, in some cases these infections cause enteritis and mesenteric lymphadenitis. Yersinia invades intestinal barrier via $\mathrm{M}$ cells. After epithelial barrier invasion, bacteria replicates within PPs and then disseminates to the major lymphatic organs, particularly MLN in humans, as well as the spleen, liver, and lungs in rodents (Handley et al., 2005).

A recent study revealed protective role of ILC3s in early host response against $Y$. enterocolitica (Seo et al., 2018). Transfer of CCR6 ${ }^{-}$ILC3s, but not CCR6 ${ }^{+}$ILC3s, derived from small intestine lamina propria of naïve $\mathrm{Rag} 1^{-/-}$mice, rescued $\mathrm{Rag}^{-/-} \mathrm{Il} 2 \mathrm{rg}^{-/-}$mice from rapid weight loss caused by $Y$. enterocolitica infection (Seo et al., 2018). IFN $\gamma$, but not IL-17A or IL-22, was critical for mice survival (Seo et al., 2018). IFN $\gamma$ is predominantly produced by NKp46 ROR $\gamma \mathrm{t}^{+}$ILC3s and only a small fraction of ILC1s and NK cells after Y. enterocolitica infection (Seo et al., 2018) (Figure 5). It remains to be determined whether ILC3s undergo plasticity during $Y$. enterocolitica infection to produce IFN $\gamma$. Surprisingly, IFN $\gamma$ production by ILC3s was dependent on LIGHT-HVEM signaling (Seo et al., 2018). Although the cellular source of LIGHT has not been identified in this study, it is known that all ILC subsets in small intestine express LIGHT and HVEM, thus both autocrine and paracrine mechanisms of HVEM activation are possible (Seo et al., 2018). Interestingly, Y. pseudotuberculosis infection is known to cause mesenteric lymphadenopathy due to disruption of lymphatic system, which results in compromised function of mucosal DCs shifted from MLN to adipose tissue (Fonseca et al., 2015). Therefore, future studies are needed to elucidate the role of ILCs in Yersinia-induced immunopathology in different tissues.

\section{Chlamydia Infection}

Chlamydiae are obligate intracellular bacteria which can cause persistent infection in mammals and birds (Yeruva et al., 2013; Rank and Yeruva, 2014). Although in the majority of animals Chlamydia resides in the GI tract and infections occur via oral-fecal route (Yeruva et al., 2013; Rank and Yeruva, 2014), Chlamydia trachomatis is associated with human genital infection and is a leading cause of sexually transmitted bacterial diseases in humans (Vasilevsky et al., 2014; Zhong, 2021). Most chlamydial infections are asymptomatic and may persist in the genital tract for a long time. The data in humans suggest that Chlamydia can also establish an infection in the GI tract and lungs (Rank and Yeruva, 2014; Howe et al., 2019). C. muridarum is a mouse pathogen commonly used to study chlamydial genital infection. It also persistently colonizes the intestine (Igietseme et al., 2001; Yeruva et al., 2013). Gastrointestinal Chlamydia infection can spread to the genital tract, leading to genital tract pathology (Dai et al., 2016; Tian et al., 2020; Zhong, 2021). In contrast, intestinal C. muridarum infection can protect 


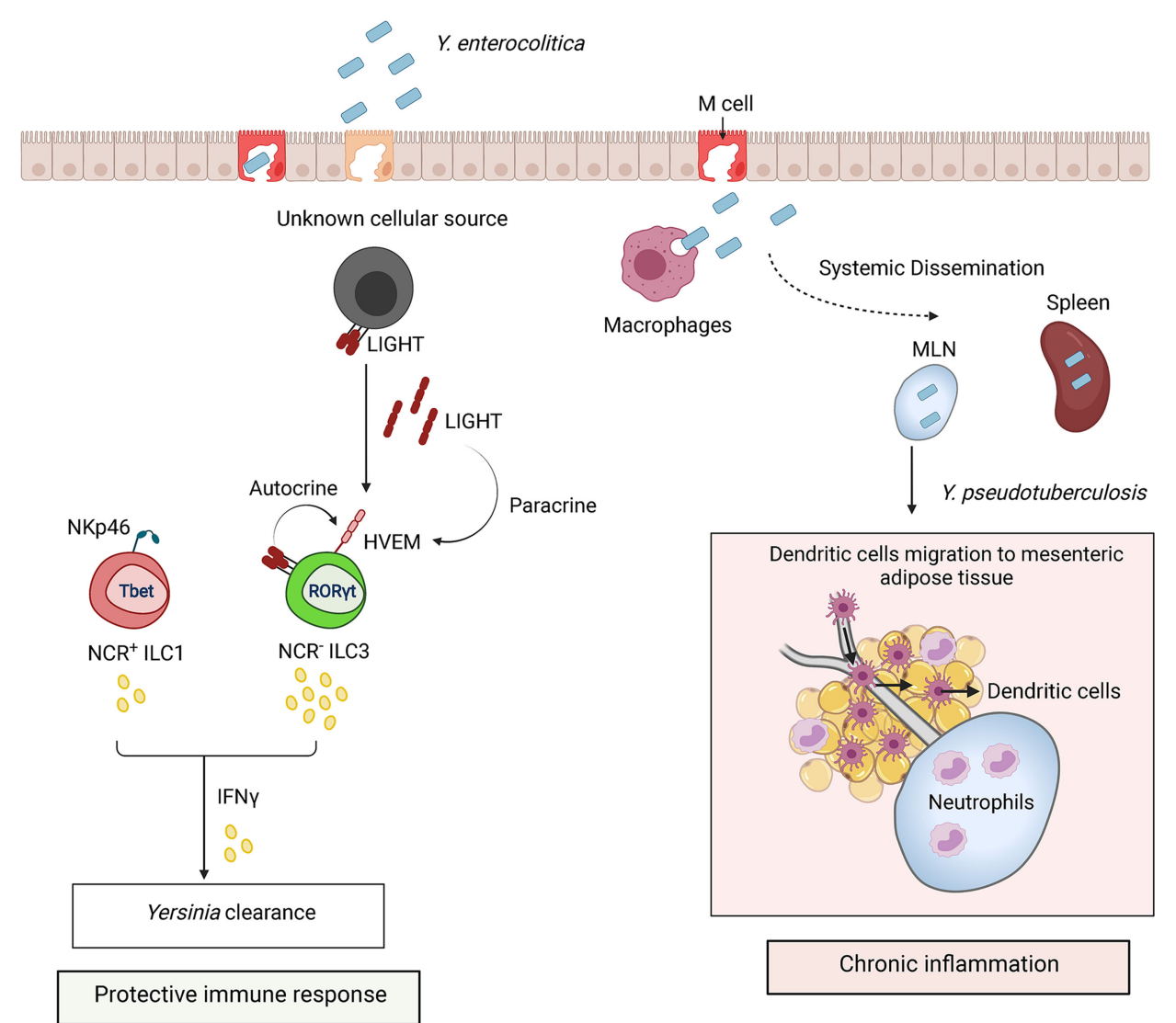

FIGURE 5 | ILCs regulate the immune response to Yersinia infection. Y. enterocolitica and Y. pseudotuberculosis invade host through microfold cells (M cells). Bacteria replicate within Peyer's patches after invasion and disseminate to mesenteric lymph nodes (MLN) and spleen. Protection against Yersinia is mediated by

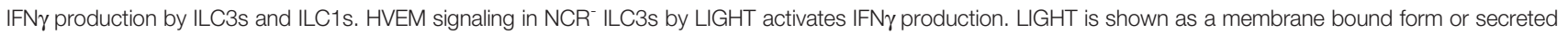
homotrimer. Sustained inflammation triggered by $Y$. pseudotuberculosis can lead to disruption of MLN lymphatics and accumulation of neutrophils which alter migration of DCs from MLN to mesenteric adipose tissue.

mice against subsequent genital tract infection, which is dependent on $\mathrm{CD}^{+} \mathrm{T}$ cells and B cells (Wang et al., 2018).

IFN $\gamma$ is critical for protection against Chlamydia infection (Johansson et al., 1997; Perry et al., 1997; Mercado et al., 2021). Although IFN $\gamma$ production by $\mathrm{CD}^{+} \mathrm{T}$ cells in response to Chlamydia infection has been described (Johansson et al., 1997; Perry et al., 1997), the role of distinct innate immune cell populations remains poorly defined.

The ILC-dependent protective mechanisms vary depending on the particular strain of Chlamydia and the route of infection. For example, IFN $\gamma$-producing NK cells are important for protection from genital C. trachomatis but not from pulmonary infection with C. pneumonia (Tseng and Rank, 1998; Rottenberg et al., 2000). Early studies demonstrated that IFN $\gamma^{+} \mathrm{NK}$ cells are recruited to the site of $C$. trachomatis infection as early as 12 hours after intravaginal inoculation of immunocompetent hosts and depletion of NK cells with anti-asialo-GM1 antibody led to impaired IFN $\gamma$ production (Tseng and Rank, 1998). However, other studies showed that Rag1 $1^{-/-}$mice depleted of NK cells are resistant to C. pheumoniae (Rottenberg et al., 2000; Rottenberg et al., 2002). Since experimental strategies to deplete NK cells with anti-NK1.1 and anti-asialo-GM1 antibodies can also target ILC1s and ILC3s, the role of distinct ILC populations in immune response to Chlamydia remained unclear.

Recent studies addressed the role of ILCs and NK cells in GI and genital tract Chlamydia infection (Koprivsek et al., 2020; Xu et al., 2020; Barth et al., 2021; He et al., 2021; Mercado et al., 2021)

(Figure 6). A study using a Chlamydia mutant strain, which is unable to maintain long-lasting colonization in the GI tract, demonstrated that IFN $\gamma$-producing $\mathrm{NK} 1.1^{+} \mathrm{ILC} 3 \mathrm{~s}$ can protect against colonization of the colon (Koprivsek et al., 2020). Furthermore, adoptive transfer of enriched ILC3s inhibited colonization of C. muridarum in the colon and restored IFN $\gamma$ production in $\mathrm{IL}_{\mathrm{R}} \mathrm{R}^{-/-}$mice (He et al., 2021). Interestingly, it appears that NK cells are dispensable for the clearance of bacteria from the colon because adoptive transfer of ROR $\gamma t^{+}$ILCs, but not ROR $\gamma \mathrm{t}^{-}$ILCs, restored colonization resistance of Chlamydia mutant in the colon (He et al., 2021). As some ROR $\gamma \mathrm{t}^{+}$ILCs expressed IFN $\gamma$, it was proposed that ex-ILC3s contribute to protection against C. muridarum mutant colonic colonization (He et al., 2021). Future 


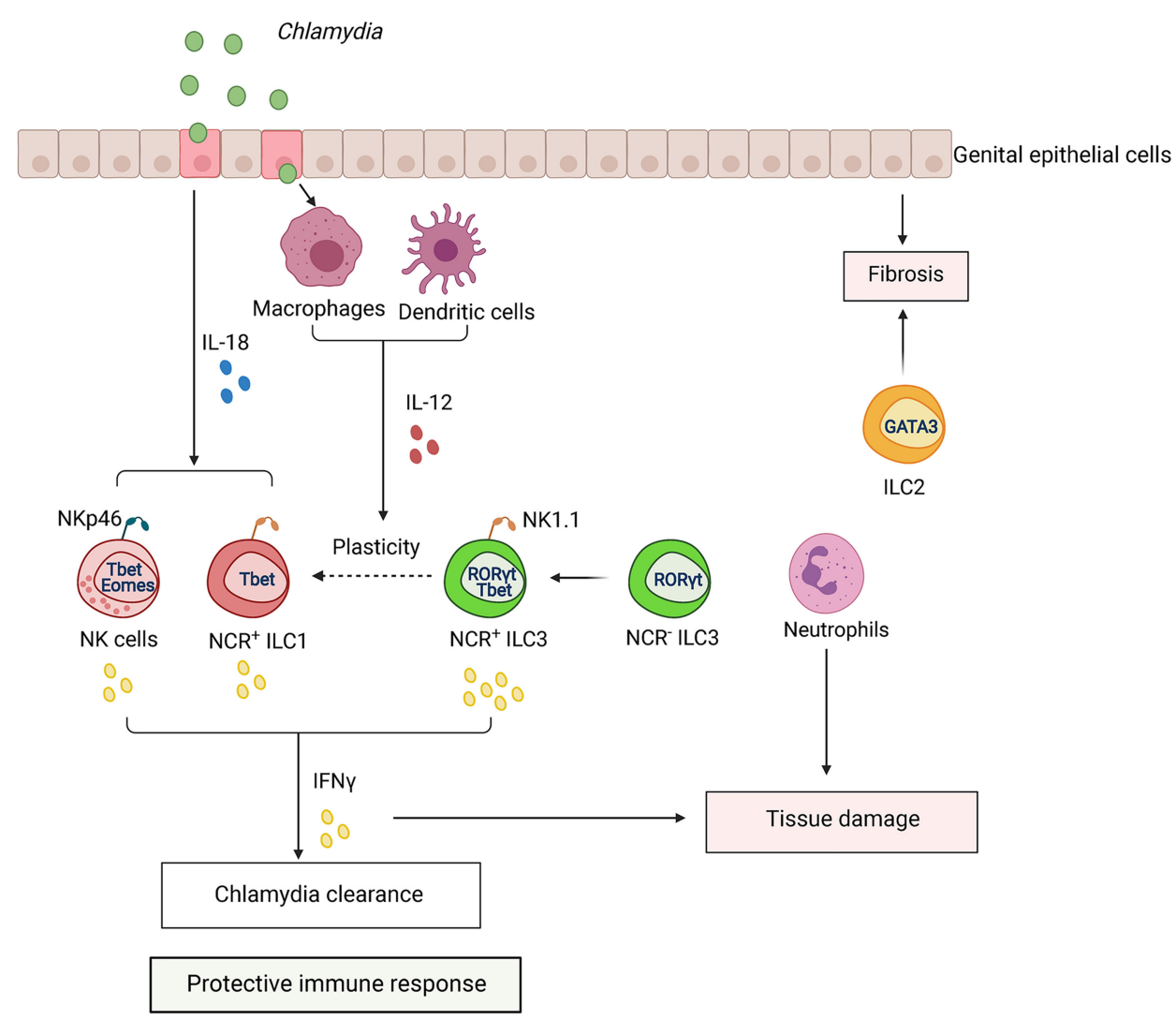

FIGURE 6 | ILCs regulate the immune response to Chlamydia infection. Chlamydia colonizes epithelium of Gl and genital tract. Infection activates dendritic cells

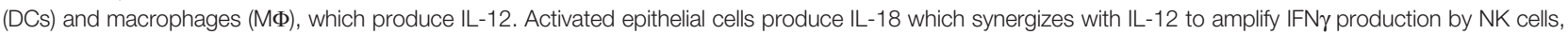
ILC1s, and ILC3s, contributing to Chlamydia clearance. Chlamydia infection induces plasticity of RORyt ${ }^{+}$ILC3s to IFNy-producing ILC1s (ex-ILC3s). CCR2 ${ }^{+}$myeloid cells can induce expansion of ILCs in the tissue. Excessive activation of ILCs and infiltration of neutrophils can lead to tissue pathology.

cell fate mapping experiments will be required to test this hypothesis.

ILCs were also found to protect against Chlamydia in the genital tract (Xu et al., 2020; Mercado et al., 2021). Thus, $\mathrm{Rag}^{-/-} \mathrm{Il}^{2} \mathrm{rg}^{-/-}$mice lacking all ILCs subsets succumbed earlier to genital C. muridarum infection compared to Rag1 ${ }^{-/}$mice (Mercado et al., 2021). Increased bacterial titers were found in genital tracts of $C$. trachomatis-infected $\mathrm{Rag}^{2 /-} \mathrm{Il}_{2} \mathrm{rg}^{-/-}$mice in comparison with $\mathrm{Rag}^{-/-}$mice (Xu et al., 2020). Depletion of NK1.1 $1^{+}$cells in Rag1 ${ }^{-/-}$mice reduced IFN $\gamma$ production and increased $C$. trachomatis titers in the endometrial tissue (Xu et al., 2020). NK1.1 $1^{+}$cell population contains a mixture of NK cells, ILC1s, and IFN $\gamma$-producing NK1. $1^{+} \mathrm{T}$-bet ${ }^{+} \mathrm{ROR} \gamma \mathrm{t}^{+} \mathrm{ILC} 3 \mathrm{~s}$. In line with this data, another study showed that ILCs can provide a source of IFN $\gamma$ during C. trachomatis infection, as ROR $\gamma t-$ and T-bet-deficient mice showed an increased bacterial burden in the genital tract (Xu et al., 2020). Additionally, depletion of NK1.1 ${ }^{+}$cells with anti-NK1.1. antibody reduced IFN $\gamma$ production and increased C. trachomatis burden in the endometrial tissue (Xu et al., 2020). Recent comprehensive analysis of ILC populations by flow cytometry during the course of genital C. muridarum infection revealed that NK cells were the predominant ILCs, and they expanded 2-3 fold during infection (from $~ 50,000$ cells in naïve mice to 150,000 cells by day 30 post infection) (Barth et al., 2021). ILC1s also expanded 5-10 fold ( 4,000 cells in naïve mice to 20,000 cells by day 30 ). In contrast, ILC3 numbers remained very low throughout the infection (100-400 cells per genital tract). The genital tract also contained a small number of ILC2s (2000-3000 cells per genital tract). Furthermore, cell fate-mapping experiments revealed that only $10 \%$ of ILC1s had a history of ROR $\gamma t$ expression (Barth et al., 2021). It remains unclear whether these very small numbers of ILC3s and ex-ILC3s could contribute to the protection against genital Chlamydia infection. The mechanism leading to specific expansion of ILC subsets in the genital tract remains to be determined and could potentially include proliferation of tissueresident cells, recruitment, and differentiation. Although RORytdeficient mice showed increased bacterial titers in the genital tract (Xu et al., 2020), other developmental defects in these mice, such as lack of lymph nodes and gut-associated lymphoid tissues could contribute to this phenotype. The role of ILC1s in protection is also unclear, as only about $25 \%$ of ILC1s produced IFN $\gamma$ on day 4 after infection, but almost none did on day 30 , although the accumulation of these cells in the genital tract continued until at least day 30 after infection (Barth et al., 2021). The role of ILC1s in Chlamydia infection remains contradictory, as $\mathrm{NKp} 46^{-1-}$ mice did not display 
reduced numbers of ILC1s (Barth et al., 2021), in contrast to previous report (Wang et al., 2018). We speculate that the contribution of distinct populations of ILCs for protection vary between genital versus GI tract infection. It is possible that local cytokine microenvironment in GI tract influenced by signals from microbiota predominantly supports expansion of IFN $\gamma$-producing ex-ILC3s, whereas genital tract infection drives expansion of IFN $\gamma$ producing NK cells and ILC1s. As IFN $\gamma$-producing NK cells and ILC1s accumulate at mucosa at the same time post infection, it will be important to define whether these subsets play unique or redundant roles during infection. Further studies using more specific genetic targeting of distinct ILC populations are required to better define the specific contribution of ILC subsets to protection following GI and genital tract infections.

Genital tract infection is known to promote inflammationassociated scarring of the oviduct that leads to hydrosalpinx (Tang et al., 2013; Lei et al., 2014). The role of ILCs in tissue pathology remains poorly understood. Interestingly, oviduct weight as an indicator of pathology correlated with expansion of NK cells and ILC1s following genital C. muridarum infection (Barth et al., 2021). Myeloid cells can promote expansion of ILCs because CCR $2^{-/-}$mice displayed reduced numbers of ILCs in the genital tract (Barth et al., 2021). Additionally, depletion of neutrophils ameliorated tissue damage in genital C. muridarum infection (Zortel et al., 2018). Thus, interplay between ILCs and other immune cell populations can shape the outcome of Chlamydia infection (Figure 6). It will be important to define in future studies why some patients infected with Chlamydia develop pathology whereas others remain asymptomatic. A shift from Th1 to Th2 immune response was suggested to promote scarring and pathology development (Barth et al., 2021). As both ILC1s and ILC2s are present in the genital tract (Doisne et al., 2015), it is possible that ILC1s and NK cells predominantly contribute to bacterial clearance and host protection whereas ILC2s can induce inflammation and fibrosis.

\section{Mycobacterium tuberculosis}

Tuberculosis disease has one of the highest fatality rates among human infections. The causative agent, Mycobacterium tuberculosis $(M t b)$, is a facultative mycobacterial pathogen which primarily resides in the phagosomes of macrophages (Podinovskaia et al., 2013). Ingestion of mycobacterium bacilli induces release of proinflammatory cytokines and chemokines to activate immune response. Early studies revealed an increased sensitivity of Rag2 $2^{-/} \mathrm{Tl} 2 \mathrm{rg}^{-/-}$mice to $M t b$ compared to $\mathrm{Rag}^{-/-}$mice, which was attributed to the lack of IFN $\gamma$-producing NK cells in Rag2 ${ }^{-/-} \mathrm{Il}_{2} \mathrm{rg}^{-/-}$mice (Feng et al., 2006). However, a recent study implicated the role of ILC3s in protective immunity to $M t b$ (Ardain et al., 2019a).

Although all ILC subsets were found in the airways, most studies were focused on ILC2s that were thought to be important for allergic airway inflammation (Halim et al., 2012; Yu et al., 2018; Xiao et al., 2021), chronic rhinosinusitis (Mjösberg et al., 2011), and asthma (McKenzie, 2014). While ILC2s are the predominant cells among ILCs in the mouse lungs in steady state, ILC3s are prevalent in human lung tissue in pulmonary disease (De Grove et al., 2016). During $M t b$ infection, ILCs become activated and accumulated in the lungs (Ardain et al., 2019a; Ardain et al., 2019b). While ILC2s accumulated at the later time points of $M t b$ infection in human and mouse lungs, ILC3s but not ILC1s rapidly accumulated in the lungs early during infection (Ardain et al., 2019a). Interestingly, the accumulation of alveolar macrophages coincided with an increase of ILC3s in the lungs (Ardain et al., 2019a). Moreover, mice lacking ILC3s exhibited reduced accumulation of alveolar macrophages and increased Mtb burden, suggesting that ILC3s contribute to early immune control of Mtb (Ardain et al., 2019a).

$M t b$ infection leads to type 1 immunity development with high levels of IFN $\gamma$ production. One study showed that IFN $\gamma^{-1-}$ mice and mice depleted of NK cells and NK1.1 ${ }^{+}$ILC1s with anti-NK1.1 antibody did not show increased bacterial titers in the lungs, suggesting that IFN $\gamma$, NK cells and NK1.1 ${ }^{+}$ILC1s are dispensable for control of early immunity to $M t b$ (Ardain et al., 2019a). Another study showed expansion of ILC1s in the lung as well as ILC1-like cells that expressed ILC1 markers T-bet, CD49a, and CD226 but were negative for NK1.1, NKp46, and Eomes (Corral et al., 2021) at later time points of infection. Furthermore, ILC1like cells could originate from ILC2s during $M t b$ infection (Corral et al., 2021). Both ILC1s and ILC1-like cells contributed to IFN $\gamma$ production (Corral et al., 2021). Moreover, protection against $M t b$ after BCG vaccination correlated with expansion of T-bet ${ }^{+}$ILC1s and IFN $\gamma$ production, indicating the protective role of ILC1s in mouse model (Steigler et al., 2018; Corral et al., 2021). Consistent with this data, recent study showed increased numbers of IFN $\gamma$ producing ILC1s in the blood of active tuberculosis patients (Pan et al., 2021).

Following pulmonary infection, activated immune cells infiltrate lungs, forming tertiary lymphoid structures known as inducible Bronchus-Associated Lymphoid Tissue (iBALT), which are important for generation of protective immune responses (Ulrichs et al., 2004; Day et al., 2010). Stromal cells express CXCL13 chemokine, which recruits lymphocytes in CXCR5dependent manner, thereby inducing formation of iBALT (Marin et al., 2019; Zeng et al., 2020). In line with results obtained in mice, high levels of CXCL13 were detected in lungs of $M t b$ patients (Ardain et al., 2019a). Moreover, CXCR5- and CD103-expressing ILC3s were detected in $M t b^{+}$human lungs (Ardain et al., 2019a), however the mechanisms underlying migration of blood-resident ILCs to the lungs upon $M t b$ infection remain unknown.

IL-22 and IL-17 are the main effector cytokines produced by ILC3s (Vivier et al., 2018). Combined deletion of IL-22 and IL-17 affected the numbers of ILC3s, including CXCR5 ${ }^{+}$ILC3s, but not ILC1s or ILC2s (Ardain et al., 2019a). Additionally, IL-22/-/IL-17 ${ }^{-/-}$ mice had higher $M t b$ burden in the lungs, suggesting that both IL-22 and IL-17 protect against $M t b$ infection (Ardain et al., 2019a). IL-23 and IL-1 $\beta$ activate production of IL-17 and IL-22 by ILC3s in the lungs (Cupedo et al., 2009; Ardain et al., 2019a). Moreover, it was shown that murine lung cells produce IL-23 in response to $M t b$, and depletion of IL-23 leads to reduction of ILC3s and alveolar macrophages (Ardain et al., 2019a). Importantly, reduced accumulation of ILC3s in the lungs correlated with decreased formation of iBALT, indicating the role of ILC3s in formation of BBALT in a CXCL13-CXCR5-dependent manner. However, the precise mechanisms by which ILC3s contribute to 
formation of iBALT and protection against $M t b$ infection still needs to be defined.

Thus, accumulating evidence suggests that ILCs contribute to $M t b$ infection, and the tissue microenvironment may change ILCs phenotype and function during lung inflammation. The relative contribution of different subsets of ILCs to $M t b$ pathology remains unclear. Moreover, it remains to be determined whether targeting of specific ILC populations could have a therapeutic effect in $M t b$ patients. Further research is also needed to dissect the relative contribution of ILC subsets and T cells to disease.

\section{Campylobacter Infection}

Campylobacter is a highly motile facultative bacteria causing the food-borne gastroenteritis called campylobacteriosis (Young et al., 2007). The main source of infection in humans is consumption of contaminated poultry where Campylobacter is a commensal. Among Campylobacter species, C. jejuni and C. coli are the major causes of acute gastroenteritis worldwide (Man, 2011; Kaakoush et al., 2015). In most cases, campylobacteriosis is self-limiting in healthy individuals; however, increasing evidence suggests that Campylobacter infection is associated with the development of autoimmune disorders affecting the nervous system and gastrointestinal tract (Ang et al., 2000; McCarthy and Giesecke, 2001; Nachamkin, 2002; Gradel et al., 2009). Moreover, patients with C. jejuni gastroenteritis are at a high risk of developing IBD (Navarro-Llavat et al., 2009; Antonelli et al., 2012; Arora et al., 2015). Since conventionally housed wild-type mice colonized with C. jejuni do not develop any adverse clinical signs or pathology (Mansfield et al., 2007; Lippert et al., 2009), most immunological studies of Campylobacter have been performed in mice with impaired IL-10 signaling. Oral inoculation of IL-10/-- mice with C. jejuni leads to colon and cecum inflammation and immunohistopathological features which resemble campylobacteriosis in humans (Mansfield et al., 2007; Mansfield et al., 2008).

Campylobacter colonizes ileum and colon, adhering to the mucus layer and invading epithelial cells. Upon bacterial invasion, epithelial cells secrete proinflammatory cytokines, including IL- 8 and TNF $\alpha$, to recruit innate immune cells for bacterial elimination at the site of the infection (Hameed, 2019) (Figure 7). Immune response to Campylobacter is characterized by the induction of mixed type 1 (IFN $\gamma$ ) and type 17 (IL-17A and IL22) cytokine responses in both humans and mice (Edwards et al., 2010; Malik et al., 2014; Al-Banna et al., 2018). Both IFN $\gamma$ and IL-17 were shown to contribute to C. jejuni-induced pathology (Malik et al., 2014; Muraoka et al., 2021). Analysis of cell types in the colon

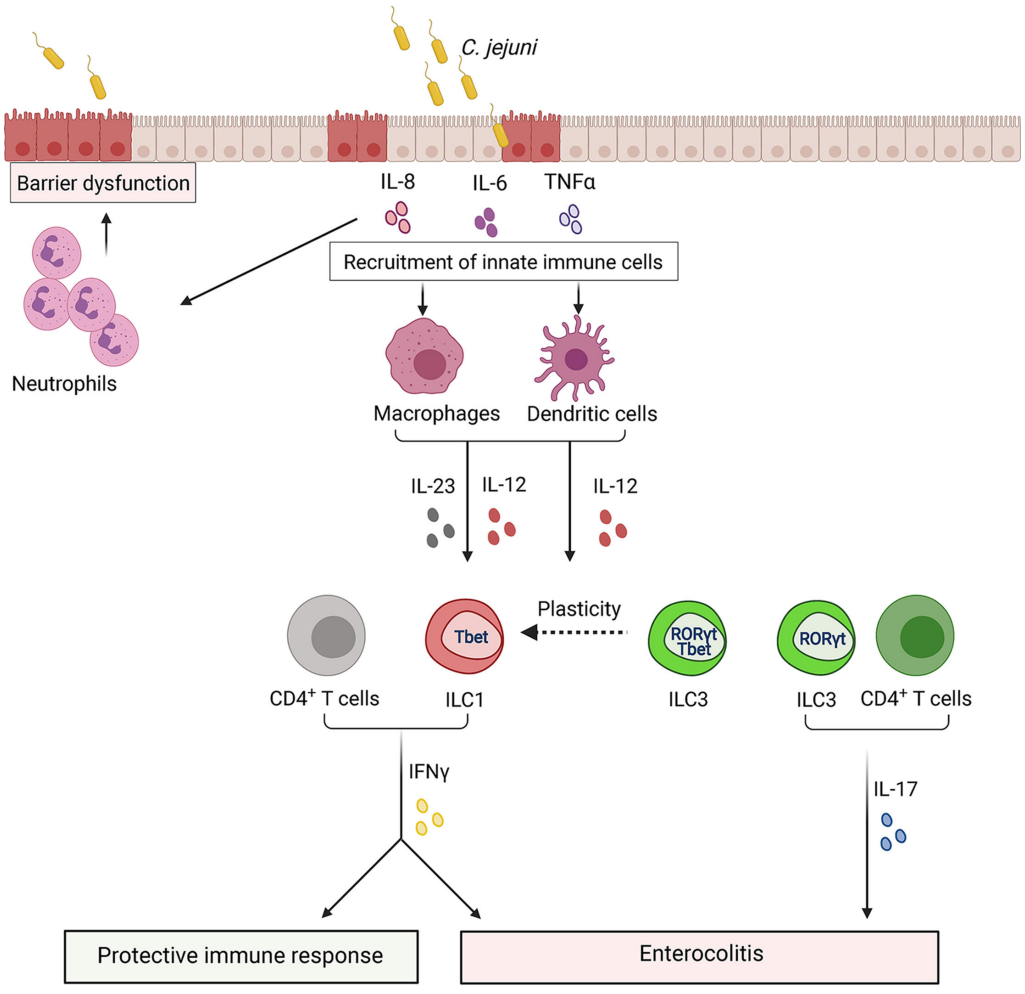

FIGURE 7 | ILCs regulate the immune response to Campylobacter jejuni. Invasion of Campylobacter into epithelial cells leads to the damage of barrier structures. In response to damage, intestinal epithelial cells secrete cytokines to recruit monocytes, macrophages, dendritic cells. These cells release IL-23 and IL-12, leading to IFN $\gamma$ production by ILCs at early stages of infection and by T cells at later stages. IFN $\gamma$ can contribute to both protective and pathogenic responses to $C$. jejuni. IFN $\gamma$ activates immune cells to help clear bacteria. Additionally, C. jejuni promotes conversion of ILC3s to IFN $\gamma$-producing ILC1s which contribute to intestinal pathology. IL-23 derived from antigen-presenting cells, such as dendritic cells, leads to IL-17 production by ILC3s and T cells which can also exacerbate colon inflammation. 
revealed that ILCs are the primary innate source of IFN $\gamma$ in early onset of C. jejuni-mediated colitis (Muraoka et al., 2021). Moreover, it was shown that $\mathrm{TCR} \beta / \delta^{-/-}$mice, which lack $\mathrm{T}$ cells, exhibit substantial intestinal inflammation in response to the infection (Muraoka et al., 2021). Depletion of $\mathrm{CD}^{+}{ }^{+} \mathrm{T}$ cells did not reduce intestinal inflammation, demonstrating that $\mathrm{CD}^{+}{ }^{+} \mathrm{T}$ cells are dispensable for colitis development in this model (Sun et al., 2012). Consistently, Rag2 $2^{-/-} \mathrm{I} 2 \mathrm{rg}^{-/-}$mice were protected from colitis, suggesting the role of ILCs in intestinal pathology at an early onset of the disease (Muraoka et al., 2021). Neutralization of IFN $\gamma$ in $\mathrm{Rag}^{-/-} \mathrm{I} 2 \mathrm{rg}^{-/-}$mice also reduced bacterial burden in the colon compared to Rag $2^{-/-}$mice, suggesting that IFN $\gamma$ - producing ILCs are dispensable for protection against C. jejuni. Additionally, neutralization of IFN $\gamma$ reduced intestinal disease in IL-10 ${ }^{-/-}$TCR $\beta /$ $\delta^{-/-}$and IL-10/- mice (Malik et al., 2014; Muraoka et al., 2021). These studies suggest that IFN $\gamma$ produced by ILCs contributes to C. jejuniinduced intestinal pathology but is dispensable for protection.

The role of IFN $\gamma$ in human campylobacteriosis remains unclear. Earlier studies demonstrated that IFN $\gamma$ can enhance killing of $C$ jejuni by macrophages (Wassenaar et al., 1997). The severity of disease was lower in healthy volunteers who exhibited increased IFN $\gamma$ production by peripheral blood mononuclear cells stimulated with heat-killed C. jejuni before experimental infection (Tribble et al., 2010). However, another study did not find a difference in the amount of $C$. jejuni-specific IFN $\gamma^{+} \mathrm{CD} 4^{+} \mathrm{T}$ cells between protected and unprotected subjects (Fimlaid et al., 2014). Development of animal models of C. jejuni-induced disease using mice reconstituted with human immune system will help to better understand the role of IFN $\gamma$ and ILCs in human disease.

Expression of natural cytotoxicity receptors $\left(\mathrm{NK} 1.1^{+}\right.$and NKp $46^{+}$) by ILC1s and ILC3s has been associated with the production of IFN $\gamma$ (Klose et al., 2013). However, growing evidence suggests that NK1.1 ILCs represent the primary source of IFN $\gamma$ during inflammation. Analysis of ILCs in the colon during C. jejuni infection revealed that NK1.1'ILCs were the main innate source of IFN $\gamma$ (Muraoka et al., 2021). Some IFN $\gamma$-producing ILCs can arise from ILC3s that downregulate ROR $\gamma t$ and upregulate T-bet expression (ex-ILC3s) (Figure 7) (Klose et al., 2013; Vivier et al., 2018). ROR $\gamma t$ cell fate-mapping experiments revealed that the majority of IFN $\gamma$-producing ILCs had a history of ROR $\gamma$ t expression, indicating that C. jejuni infection facilitates conversion of ILC3s to ILC1s (Muraoka et al., 2021). The mechanism leading to ILC3>ILC1 plasticity during C. jejuni infection remains poorly understood. ILC3s $>$ ILC1s plasticity was observed in response to IL-12 in human samples (Bernink et al., 2015). IL-12 levels in the colon are increased during C. jejuni infection (Edwards et al., 2010; Malik et al., 2014; Muraoka et al., 2021). Therefore, it is possible that IL-12 regulates the plasticity of ILCs. However, additional studies are required to test this hypothesis.

C. jejuni infection enhances the production of IL-17, IL-22 and IL-23 (Malik et al., 2014; Muraoka et al., 2021). Monocytederived dendritic cells from human PBMCs showed upregulation of both IL-17 and IL-22 cytokines after C. jejuni infection (Edwards et al., 2010). A recent study revealed IL-23 as a critical driver of inflammation during C. jejuni infection (Jing et al., 2020). Additionally, previous studies showed the pathogenic role of IL-23 in other models of infectious colitis (Kullberg et al., 2006; Buonomo et al., 2013). IL-23 is a wellknown inducer of IL-22 and IL-17. Consistently, IL-23-deficient mice displayed reduced intestinal pathology and low levels of IFN $\gamma$, IL-17 and IL-22 in the colon following C. jejuni infection (Jing et al., 2020). However, in contrast to IFN $\gamma$ and IL-17, abrogation of IL-22 signaling in mice with impaired IL-10 signaling did not have impact on C. jejuni-induced colitis and bacterial clearance (Jing et al., 2020). Interestingly, in another study in IL-10-sufficient mice, IL-22 deficiency led to increased bacterial burden in the colon (Heimesaat et al., 2016), suggesting that differences in intestinal microenvironment can affect C. jejuni colonization and disease development. Furthermore, IL-23 induced IL-17 and IFN $\gamma$ by ILC1s and ILC3s, promoting colon inflammation during the early stage of $C$. jejuni infection (Figure 7) (Jing et al., 2020). IL-17 is also known as an important activator of innate immune responses that induce neutrophil recruitment (Pappu et al., 2012). However, neutrophils can also contribute to intestinal pathology during C. jejuni infection (Sun et al., 2012).

Together, these studies demonstrate that ILCs are critical for the initiation of inflammatory immune responses against C. jejuni. Moreover, ILC3s undergo transdifferentiation to ILC1s during infection. However, there are many critical questions that remain to be addressed. Whether ILC subsets contribute to intestinal pathology in human campylobacteriosis? Whether effects of ILCs in immune response depend on the Campylobacter strain and immunological status of the host? Additionally, host microbiota can also regulate ILCs functions and cooperation of ILCs with other immune cells (Mortha et al., 2014). Therefore, understanding the role of microbiota in activation and plasticity of ILCs during C. jejuni infection will better define mechanisms of $C$. jejuni-induced intestinal pathology.

\section{CONCLUSIONS}

Over the last ten years research has identified ILCs as a heterogeneous family of innate immune cells that have very diverse functions in different barrier tissues. The precise role of ILCs is context-dependent and is regulated by tissue microenvironment. The environmental factors, including commensal microbiota and pathogens, can influence immune homeostasis and regulate plasticity and functions of ILCs. Although ILCs comprise a relatively minor cell population compared to other immune cell types, it is now well appreciated that while ILCs are essential for the maintenance of tissue homeostasis and elimination of pathogens, they can also contribute to chronic inflammation and tissue pathology.

Despite significant progress that has been made in understanding the function of ILCs in homeostatic conditions and during infection, many questions still remain. Under inflammatory conditions cytokines and tissue factors can change ILC composition. Depending on the type of signal, ILCs can transdifferentiate and 
TABLE 1 | The role of ILCs in intracellular pathogen infection.

\begin{tabular}{|c|c|c|c|c|c|}
\hline Pathogen & ILC subset & Tissue & Cytokine & Role & References \\
\hline Toxoplasma gondii & $\begin{array}{l}\text { NK, ILC1 } \\
\text { ILC3 }\end{array}$ & Small intestine & $\begin{array}{l}\mathrm{IFN} \gamma \\
\mathrm{IL}-22\end{array}$ & $\begin{array}{l}\text { Protection } \\
\text { Pathology }\end{array}$ & $\begin{array}{l}\text { (Klose et al., 2014; Lopez-Yglesias et al., 2021) } \\
\text { (Munoz et al., 2015) }\end{array}$ \\
\hline Salmonella typhimurium & ILC1, NCR ${ }^{+}$ILC3 & Large intestine & $\mathrm{IFN} \gamma$ & Dual role & (Klose et al., 2013; Yin et al., 2018) \\
\hline Listeria monocytogenes & $\mathrm{NK}, \mathrm{ILC} 1, \mathrm{NCR}^{+}$ILC3 & Small intestine & $\mathrm{IFN} \gamma$ & Protection & (Reynders et al., 2011; Yin et al., 2018; Dulson et al., 2019) \\
\hline Yersinia enterocolitica & NCRILC3 & Small intestine & $\mathrm{IFN} \gamma$ & Protection & (Seo et al., 2018) \\
\hline Chlamydia muridarum & $\mathrm{NCR}^{+}$ILC3 & Large intestine & $\mathrm{IFN} \gamma$ & Protection & (Koprivsek et al., 2020; He et al., 2021) \\
\hline Chlamydia trachomatis & NK, ILC1, NCR ${ }^{+}$ILC3 & Genital tract & $\mathrm{IFN} \gamma$ & Protection & (Xu et al., 2020; Barth et al., 2021) \\
\hline Mycobacterium tuberculosis & $\begin{array}{l}\text { ILC3 } \\
\text { ILC1 }\end{array}$ & Lungs & $\begin{array}{l}\mathrm{IL}-22 / \mathrm{IL}-17 \\
\mathrm{IFN} \gamma\end{array}$ & $\begin{array}{l}\text { Protection } \\
\text { Protection }\end{array}$ & $\begin{array}{l}\text { (Ardain et al., 2019) } \\
\text { (Corral et al., 2021; Pan et al., 2021) }\end{array}$ \\
\hline Campylobacter jejuni & $\begin{array}{l}\text { ILC1 } \\
\text { NCR'ILC3 }\end{array}$ & Large intestine & $\begin{array}{l}\mathrm{IFN} \gamma \\
\mathrm{IFN} \gamma / \mathrm{IL}-17\end{array}$ & Dual role & $\begin{array}{l}\text { (Muraoka et al., 2021) } \\
\text { (Jing et al., 2020) }\end{array}$ \\
\hline Plasmodium berghei & ILC2 & Spleen & $\begin{array}{l}\text { IL-4/ } \\
\text { IL-5/IL-13 }\end{array}$ & Protection & (Besnard et al., 2015) \\
\hline
\end{tabular}

change the outcome of the disease. Accordingly, both ILC1s and ILC3s can produce IFN $\gamma$ under inflammatory conditions, which may have different effects during acute and chronic infections. It is important to study the relative functions of specific ILC subsets under physiological and inflammatory conditions because different subsets of ILCs can be protective or pathogenic (Table 1). Additional studies aimed to characterize the effects of environmental cues, such as dietary factors, metabolites and inflammatory mediators, on ILC development and function, will further advance our understanding of ILCs contribution to the pathogenesis of infectious diseases.

Although recent progress has revealed the role of ILCs in shaping the adaptive immune response by direct cell contact or by cytokine production, a lot more is still to be explored to uncover the function of ILCs in regulating the adaptive immune response following different infections in various tissues. For example, it is still unclear how ILCs regulate Th1 and Th17 immune responses during inflammation, and whether these mechanisms are context-dependent. Identification of mechanisms by which ILCs regulate the adaptive immune response across different infections will provide insights into the specific factors that may control the disease initiation and progression. The role of ILCs in protection and pathogenesis of human infections still needs to be better defined.

Over the last few years many small molecules and monoclonal antibodies that potentially may directly or indirectly target effector functions of ILCs, have been developed, such as JAK inhibitors (Schwartz et al., 2017; Robinette et al., 2018), TNF inhibitors, vedolizumab (anti- $\alpha 4 \beta 7$ integrin $\mathrm{mAb}$ ) (Cobb and Verneris, 2021) and ustekinumab (IL-12/23p40 mAb) (Creyns

\section{REFERENCES}

Ahmad, R., Sorrell, M. F., Batra, S. K., Dhawan, P., and Singh, A. B. (2017). Gut Permeability and Mucosal Inflammation: Bad, Good or Context Dependent. Mucosal Immunol. 10, 307-317. doi: 10.1038/mi.2016.128

Al-Banna, N. A., Cyprian, F., and Albert, M. J. (2018). Cytokine Responses in Campylobacteriosis: Linking Pathogenesis to Immunity. Cytokine Growth Factor Rev. 41, 75-87. doi: 10.1016/j.cytogfr.2018.03.005

Amaldi, I., Reith, W., Berte, C., and Mach, B. (1989). Induction of Hla Class Ii Genes by Ifn-Gamma is Transcriptional and Requires a Trans-Acting Protein. J. Immunol. (Baltimore Md. 1950) 142(3), 999-1004. et al., 2020; Cobb and Verneris, 2021). However, their selectivity and effects on ILCs are not fully characterized and need to be proven. Whether the application of these molecules will be beneficial for targeting ILCs in infectious diseases needs to be determined. Future work should focus on understanding the protective and pathogenic mechanisms of ILCs in different infections combining knowledge obtained from mouse models and human studies. These findings could uncover more specific targets for disease treatment.

\section{AUTHOR CONTRIBUTIONS}

Study concept and design: AK and AT. Wrote and edited manuscript: AK, EK, and AT. All authors contributed to the article and approved the submitted version.

\section{FUNDING}

This research was supported by grants from NIH (AI135574, NS112263). AT was supported by the Max and Minnie Tomerlin Voelcker Fund, and William and Ella Owens Medical Research Foundation.

\section{ACKNOWLEDGMENTS}

The authors thank Anna Tumanova for editing manuscript. Figures were created with BioRender.com. 
Ardain, A., Porterfield, J. Z., Kloverpris, H. N., and Leslie, A. (2019b). Type 3 Ilcs in Lung Disease. Front. Immunol. 10, 92. doi: 10.3389/fimmu.2019.00092

Arora, Z., Mukewar, S., Wu, X., and Shen, B. (2015). Risk Factors and Clinical Implication of Superimposed Campylobacter Jejuni Infection in Patients With Underlying Ulcerative Colitis. Gastroenterol. Rep. 4, 287-292. doi: 10.1093/ gastro/gov029

Bal, S. M., Bernink, J. H., Nagasawa, M., Groot, J., Shikhagaie, M. M., Golebski, K., et al. (2016). 1 $\beta$, Il-4 and Il-12 Control the Fate of Group 2 Innate Lymphoid Cells in Human Airway Inflammation in the Lungs. Nat. Immunol. 17, 636645. doi: $10.1038 /$ ni. 3444

Bal, S. M., Golebski, K., and Spits, H. (2020). Plasticity of Innate Lymphoid Cell Subsets. Nat. Rev. Immunol. 20, 552-565. doi: 10.1038/s41577-020-0282-9

Bancerz-Kisiel, A., Pieczywek, M., Łada, P., and Szweda, W. (2018). The Most Important Virulence Markers of Yersinia Enterocolitica and Their Role During Infection. Genes 9, 235. doi: 10.3390/genes9050235

Bando, J. K., Gilfillan, S., Di Luccia, B., Fachi, J. L., Sécca, C., Cella, M., et al. (2020). Ilc2s are the Predominant Source of Intestinal Ilc-Derived Il-10. J. Exp. Med. 217 (2), e20191520. doi: 10.1084/jem.20191520

Bar-Ephraïm, Y. E., and Mebius, R. E. (2016). Innate Lymphoid Cells in Secondary Lymphoid Organs. Immunol. Rev. 271, 185-199. doi: 10.1111/imr.12407

Barth, S., Kirschnek, S., Ortmann, N., Tanriver, Y., and Häcker, G. (2021). The Reaction of Innate Lymphoid Cells in the Mouse Female Genital Tract to Chlamydial Infection. Infect. Immun. 89 (11), Iai0080020. doi: 10.1128/ iai.00800-20

Beck, K., Ohno, H., and Satoh-Takayama, N. (2020). Innate Lymphoid Cells: Important Regulators of Host-Bacteria Interaction for Border Defense. Microorganisms 8 (9), 1342. doi: 10.3390/microorganisms8091342

Bernink, J. H., Krabbendam, L., Germar, K., de Jong, E., Gronke, K., KofoedNielsen, M., et al. (2015). Interleukin-12 and -23 Control Plasticity of Cd127(+) Group 1 and Group 3 Innate Lymphoid Cells in the Intestinal Lamina Propria. Immunity 43, 146-160. doi: 10.1016/j.immuni.2015.06.019

Bernink, J. H., Peters, C. P., Munneke, M., te Velde, A. A., Meijer, S. L., Weijer, K., et al. (2013). Human Type 1 Innate Lymphoid Cells Accumulate in Inflamed Mucosal Tissues. Nat. Immunol. 14, 221-229. doi: 10.1038/ni.2534

Besnard, A. G., Guabiraba, R., Niedbala, W., Palomo, J., Reverchon, F., Shaw, T. N., et al. (2015). Il-33-Mediated Protection Against Experimental Cerebral Malaria is Linked to Induction of Type 2 Innate Lymphoid Cells, M2 Macrophages and Regulatory T Cells. PloS Pathog. 11, e1004607. doi: 10.1371/journal.ppat.1004607

Bielecki, P., Riesenfeld, S. J., Hütter, J.-C., Torlai Triglia, E., Kowalczyk, M. S., Ricardo-Gonzalez, R. R., et al. (2021). Skin-Resident Innate Lymphoid Cells Converge on a Pathogenic Effector State. Nature 592, 128-132. doi: 10.1038/ s41586-021-03188-w

Blumenthal, A., Nagalingam, G., Huch, J. H., Walker, L., Guillemin, G. J., Smythe, G. A., et al. (2012). M. Tuberculosis Induces Potent Activation of Ido-1, But This is Not Essential for the Immunological Control of Infection. PloS One 7, e37314. doi: 10.1371/journal.pone.0037314

Bogdan, C. (2015). Nitric Oxide Synthase in Innate and Adaptive Immunity: An Update. Trends Immunol. 36, 161-178. doi: 10.1016/j.it.2015.01.003

Braverman, J., and Stanley, S. A. (2017). Nitric Oxide Modulates Macrophage Responses to Mycobacterium Tuberculosis Infection Through Activation of Hif-1 $\alpha$ and Repression of Nf-kb. J. Immunol. (Baltimore Md. 1950) 199, 18051816. doi: 10.4049/jimmunol.1700515

Brüggen, M. C., Bauer, W. M., Reininger, B., Clim, E., Captarencu, C., Steiner, G. E., et al. (2016). In Situ Mapping of Innate Lymphoid Cells in Human Skin: Evidence for Remarkable Differences Between Normal and Inflamed Skin. J. Invest. Dermatol. 136, 2396-2405. doi: 10.1016/j.jid.2016.07.017

Buonocore, S., Ahern, P. P., Uhlig, H. H., Ivanov, I. I., Littman, D. R., Maloy, K. J., et al. (2010). Innate Lymphoid Cells Drive Interleukin-23-Dependent Innate Intestinal Pathology. Nature 464, 1371-1375. doi: 10.1038/nature08949

Buonomo, E. L., Madan, R., Pramoonjago, P., Li, L., Okusa, M. D., and Petri, W. A. Jr. (2013). Role of Interleukin 23 Signaling in Clostridium Difficile Colitis. J. Infect. Dis. 208, 917-920. doi: 10.1093/infdis/jit277

Cardoso, V., Chesné, J., Ribeiro, H., García-Cassani, B., Carvalho, T., Bouchery, T., et al. (2017). Neuronal Regulation of Type 2 Innate Lymphoid Cells via Neuromedin U. Nature 549, 277-281. doi: 10.1038/nature23469

Casadevall, A., and Fang, F. C. (2020). The Intracellular Pathogen Concept. Mol. Microbiol. 113, 541-545. doi: 10.1111/mmi.14421
Castellanos, J. G., Woo, V., Viladomiu, M., Putzel, G., Lima, S., Diehl, G. E., et al. (2018). Microbiota-Induced Tnf-Like Ligand 1a Drives Group 3 Innate Lymphoid Cell-Mediated Barrier Protection and Intestinal T Cell Activation During Colitis. Immunity 49, 1077-1189.e5. doi: 10.1016/j.immuni.2018.10.014

Cayrol, C., and Girard, J. P. (2019). Innate Lymphoid Cells in Asthmatic Patients. J. Allergy Clin. Immunol. 143, 1739-1741. doi: 10.1016/j.jaci.2019.03.011

Chelakkot, C., Ghim, J., and Ryu, S. H. (2018). Mechanisms Regulating Intestinal Barrier Integrity and its Pathological Implications. Exp. Mol. Med. 50, 1-9. doi: 10.1038/s12276-018-0126-x

Chen, W., Lai, D., Li, Y., Wang, X., Pan, Y., Fang, X., et al. (2021). NeuronalActivated Ilc2s Promote Il-17a Production in Lung $\gamma \delta$ T Cells During Sepsis. Front. Immunol. 12, 670676. doi: 10.3389/fimmu.2021.670676

Chua, H. H., Chou, H. C., Tung, Y. L., Chiang, B. L., Liao, C. C., Liu, H. H., et al. (2018). Intestinal Dysbiosis Featuring Abundance of Ruminococcus Gnavus Associates With Allergic Diseases in Infants. Gastroenterology 154, 154-167. doi: 10.1053/j.gastro.2017.09.006

Chun, E., Lavoie, S., Fonseca-Pereira, D., Bae, S., Michaud, M., Hoveyda, H. R., et al. (2019). Metabolite-Sensing Receptor Ffar2 Regulates Colonic Group 3 Innate Lymphoid Cells and Gut Immunity. Immunity 51, 871-884.e6. doi: 10.1016/j.immuni.2019.09.014

Clark, J. T., Christian, D. A., Gullicksrud, J. A., Perry, J. A., Park, J., Jacquet, M., et al. (2021). Il-33 Promotes Innate Lymphoid Cell-Dependent Ifn- $\gamma$ Production Required for Innate Immunity to Toxoplasma Gondii. eLife 10, e65614. doi: 10.7554/eLife.65614

Cobb, L. M., and Verneris, M. R. (2021). Therapeutic Manipulation of Innate Lymphoid Cells. JCI Insight 6(6), e146006. doi: 10.1172/jci.insight.146006

Colonna, M. (2009). Interleukin-22-Producing Natural Killer Cells and Lymphoid Tissue Inducer-Like Cells in Mucosal Immunity. Immunity 31, 15-23. doi: 10.1016/j.immuni.2009.06.008

Corral, D., Charton, A., Krauss, M. Z., Blanquart, E., Levillain, F., Lefrançais, E., et al. (2021). Metabolic Control of Type 2 Innate Lymphoid Cells Plasticity Toward Protective Type 1-Like Cells During Mycobacterium Tuberculosis Infection. bioRxiv. doi: 10.1101/2021.01.19.427257

Couturier-Maillard, A., Froux, N., Piotet-Morin, J., Michaudel, C., Brault, L., Le Bérichel, J., et al. (2018). Interleukin-22-Deficiency and Microbiota Contribute to the Exacerbation of Toxoplasma Gondii-Induced Intestinal Inflammation. Mucosal Immunol. 11, 1181-1190. doi: 10.1038/s41385-018-0005-8

Crellin, N. K., Trifari, S., Kaplan, C. D., Satoh-Takayama, N., Di Santo, J. P., and Spits, H. (2010). Regulation of Cytokine Secretion in Human Cd127(+) LtiLike Innate Lymphoid Cells by Toll-Like Receptor 2. Immunity 33, 752-764. doi: 10.1016/j.immuni.2010.10.012

Creyns, B., Jacobs, I., Verstockt, B., Cremer, J., Ballet, V., Vandecasteele, R., et al. (2020). Biological Therapy in Inflammatory Bowel Disease Patients Partly Restores Intestinal Innate Lymphoid Cell Subtype Equilibrium. Front. Immunol. 11, 1847. doi: 10.3389/fimmu.2020.01847

Cupedo, T., Crellin, N. K., Papazian, N., Rombouts, E. J., Weijer, K., Grogan, J. L., et al. (2009). Human Fetal Lymphoid Tissue-Inducer Cells are Interleukin 17Producing Precursors to Rorc+ Cd127+ Natural Killer-Like Cells. Nat. Immunol. 10, 66-74. doi: 10.1038/ni.1668

Dai, J., Zhang, T., Wang, L., Shao, L., Zhu, C., Zhang, Y., et al. (2016). Intravenous Inoculation With Chlamydia Muridarum Leads to a Long-Lasting Infection Restricted to the Gastrointestinal Tract. Infect. Immun. 84, 2382-2388. doi: 10.1128/IAI.00432-16

Darwich, L., Coma, G., Peña, R., Bellido, R., Blanco, E. J., Este, J. A., et al. (2009). Secretion of Interferon-Gamma by Human Macrophages Demonstrated at the Single-Cell Level After Costimulation With Interleukin (Il)-12 Plus Il-18. Immunology 126, 386-393. doi: 10.1111/j.1365-2567.2008.02905.x

Daussy, C., Faure, F., Mayol, K., Viel, S., Gasteiger, G., Charrier, E., et al. (2014). TBet and Eomes Instruct the Development of Two Distinct Natural Killer Cell Lineages in the Liver and in the Bone Marrow. J. Exp. Med. 211, 563-577. doi: $10.1084 /$ jem. 20131560

Day, T. A., Koch, M., Nouailles, G., Jacobsen, M., Kosmiadi, G. A., Miekley, D., et al. (2010). Secondary Lymphoid Organs are Dispensable for the Development of T-Cell-Mediated Immunity During Tuberculosis. Eur. J. Immunol. 40, 1663-1673. doi: 10.1002/eji.201040299

Decker, T., Stockinger, S., Karaghiosoff, M., Müller, M., and Kovarik, P. (2002). Ifns and Stats in Innate Immunity to Microorganisms. J. Clin. Invest. 109, 1271-1277. doi: $10.1172 /$ jci15770 
De Grove, K. C., Provoost, S., Verhamme, F. M., Bracke, K. R., Joos, G. F., Maes, T., et al. (2016). Characterization and Quantification of Innate Lymphoid Cell Subsets in Human Lung. PloS One 11, e0145961. doi: 10.1371/journal.pone.0145961

Denkers, E. Y., Gazzinelli, R. T., Martin, D., and Sher, A. (1993). Emergence of Nk1.1+ Cells as Effectors of Ifn-Gamma Dependent Immunity to Toxoplasma Gondii in Mhc Class I-Deficient Mice. J. Exp. Med. 178, 1465-1472. doi: 10.1084/jem.178.5.1465

Doisne, J. M., Balmas, E., Boulenouar, S., Gaynor, L. M., Kieckbusch, J., Gardner, L., et al. (2015). Composition, Development, and Function of Uterine Innate Lymphoid Cells. J. Immunol. (Baltimore Md. 1950) 195, 3937-3945. doi: 10.4049/jimmunol.1500689

Dolowschiak, T., Mueller, A. A., Pisan, L. J., Feigelman, R., Felmy, B., Sellin, M. E., et al. (2016). Ifn- $\gamma$ Hinders Recovery From Mucosal Inflammation During Antibiotic Therapy for Salmonella Gut Infection. Cell Host Microbe 20, 238249. doi: 10.1016/j.chom.2016.06.008

Dulson, S. J., Watkins, E. E., Crossman, D. K., and Harrington, L. E. (2019). Stat4 Directs a Protective Innate Lymphoid Cell Response to Gastrointestinal Infection. J. Immunol. (Baltimore Md. 1950) 203, 2472-2484. doi: 10.4049/ jimmunol.1900719

Dunay, I. R., Damatta, R. A., Fux, B., Presti, R., Greco, S., Colonna, M., et al. (2008). Grl(+) Inflammatory Monocytes are Required for Mucosal Resistance to the Pathogen Toxoplasma Gondii. Immunity 29, 306-317. doi: 10.1016/ j.immuni.2008.05.019

Dunay, I. R., and Diefenbach, A. (2018). Group 1 Innate Lymphoid Cells in Toxoplasma Gondii Infection. Parasite Immunol. 40(2), e12516. doi: 10.1111/ pim. 12516

Eberl, G., Marmon, S., Sunshine, M. J., Rennert, P. D., Choi, Y., and Littman, D. R. (2004). An Essential Function for the Nuclear Receptor Rorgamma(T) in the Generation of Fetal Lymphoid Tissue Inducer Cells. Nat. Immunol. 5, 64-73. doi: $10.1038 /$ ni1022

Edwards, L. A., Nistala, K., Mills, D. C., Stephenson, H. N., Zilbauer, M., Wren, B. W., et al. (2010). Delineation of the Innate and Adaptive T-Cell Immune Outcome in the Human Host in Response to Campylobacter Jejuni Infection. PloS One 5, e15398. doi: 10.1371/journal.pone.0015398

Eriguchi, Y., Nakamura, K., Yokoi, Y., Sugimoto, R., Takahashi, S., Hashimoto, D., et al. (2018). Essential Role of Ifn- $\gamma$ in T Cell-Associated Intestinal Inflammation. JCI Insight 3 (18), e121886. doi: 10.1172/jci.insight.121886

Feng, C. G., Kaviratne, M., Rothfuchs, A. G., Cheever, A., Hieny, S., Young, H. A., et al. (2006). Nk Cell-Derived Ifn-Gamma Differentially Regulates Innate Resistance and Neutrophil Response in T Cell-Deficient Hosts Infected With Mycobacterium Tuberculosis. J. Immunol. (Baltimore Md. 1950) 177, 70867093. doi: $10.4049 /$ jimmunol.177.10.7086

Ferreira, A. C. F., Szeto, A. C. H., Heycock, M. W. D., Clark, P. A., Walker, J. A., Crisp, A., et al. (2021). Roro is a Critical Checkpoint for T Cell and Ilc2 Commitment in the Embryonic Thymus. Nat. Immunol. 22, 166-178. doi: 10.1038/s41590-020-00833-w

Fimlaid, K. A., Lindow, J. C., Tribble, D. R., Bunn, J. Y., Maue, A. C., and Kirkpatrick, B. D. (2014). Peripheral Cd4+ T Cell Cytokine Responses Following Human Challenge and Re-Challenge With Campylobacter Jejuni. PloS One 9, e112513. doi: 10.1371/journal.pone.0112513

Fonseca, D. M., Hand, T. W., Han, S. J., Gerner, M. Y., Glatman Zaretsky, A., Byrd, A. L., et al. (2015). Microbiota-Dependent Sequelae of Acute Infection Compromise Tissue-Specific Immunity. Cell 163, 354-366. doi: 10.1016/ j.cell.2015.08.030

Forkel, M., and Mjosberg, J. (2016). Dysregulation of Group 3 Innate Lymphoid Cells in the Pathogenesis of Inflammatory Bowel Disease. Curr. Allergy Asthma Rep. 16, 73. doi: 10.1007/s11882-016-0652-3

Forkel, M., van Tol, S., Hoog, C., Michaelsson, J., Almer, S., and Mjosberg, J. (2019). Distinct Alterations in the Composition of Mucosal Innate Lymphoid Cells in Newly Diagnosed and Established Crohn's Disease and Ulcerative Colitis. J. Crohns Colitis 13, 67-78. doi: 10.1093/ecco-jcc/jjy119

Frucht, D. M., Fukao, T., Bogdan, C., Schindler, H., O'Shea, J. J., and Koyasu, S. (2001). Ifn-Gamma Production by Antigen-Presenting Cells: Mechanisms Emerge. Trends Immunol. 22, 556-560. doi: 10.1016/s1471-4906(01)02005-1

Fuchs, A., Vermi, W., Lee, J. S., Lonardi, S., Gilfillan, S., Newberry, R. D., et al. (2013). Intraepithelial Type 1 Innate Lymphoid Cells are a Unique Subset of Il12- and Il-15-Responsive Ifn-Gamma-Producing Cells. Immunity 38, 769-781. doi: 10.1016/j.immuni.2013.02.010
Gao, Y., Souza-Fonseca-Guimaraes, F., Bald, T., Ng, S. S., Young, A., Ngiow, S. F., et al. (2017). Tumor Immunoevasion by the Conversion of Effector Nk Cells Into Type 1 Innate Lymphoid Cells. Nat. Immunol. 18, 1004-1015. doi: 10.1038/ni.3800

Gasteiger, G., Fan, X., Dikiy, S., Lee, S. Y., and Rudensky, A. Y. (2015). Tissue Residency of Innate Lymphoid Cells in Lymphoid and Nonlymphoid Organs. Science 350, 981-985. doi: 10.1126/science.aac9593

Gazzinelli, R. T., Wysocka, M., Hayashi, S., Denkers, E. Y., Hieny, S., Caspar, P., et al. (1994). Parasite-Induced Il-12 Stimulates Early Ifn-Gamma Synthesis and Resistance During Acute Infection With Toxoplasma Gondii. J. Immunol. 153 (6), 2533-2543.

Geremia, A., Arancibia-Cárcamo, C. V., Fleming, M. P., Rust, N., Singh, B., Mortensen, N. J., et al. (2011). Il-23-Responsive Innate Lymphoid Cells are Increased in Inflammatory Bowel Disease. J. Exp. Med. 208, 1127-1133. doi: $10.1084 /$ jem.20101712

Goldszmid, R. S., Bafica, A., Jankovic, D., Feng, C. G., Caspar, P., Winkler-Pickett, R., et al. (2007). Tap-1 Indirectly Regulates Cd4 $+\mathrm{T}$ Cell Priming in Toxoplasma Gondii Infection by Controlling Nk Cell Ifn-Gamma Production. J. Exp. Med. 204, 2591-2602. doi: 10.1084/jem.20070634

Goldszmid, R. S., Caspar, P., Rivollier, A., White, S., Dzutsev, A., Hieny, S., et al. (2012). Nk Cell-Derived Interferon-Gamma Orchestrates Cellular Dynamics and the Differentiation of Monocytes Into Dendritic Cells at the Site of Infection. Immunity 36, 1047-1059. doi: 10.1016/j.immuni.2012.03.026

Golebski, K., Layhadi, J. A., Sahiner, U., Steveling-Klein, E. H., Lenormand, M. M., Li, R. C. Y., et al. (2021). Induction of Il-10-Producing Type 2 Innate Lymphoid Cells by Allergen Immunotherapy is Associated With Clinical Response. Immunity 54, 291-307.e7. doi: 10.1016/j.immuni.2020.12.013

Gordon, S. M., Chaix, J., Rupp, L. J., Wu, J., Madera, S., Sun, J. C., et al. (2012). The Transcription Factors T-Bet and Eomes Control Key Checkpoints of Natural Killer Cell Maturation. Immunity 36, 55-67. doi: 10.1016/ j.immuni.2011.11.016

Goto, Y., Obata, T., Kunisawa, J., Sato, S., Ivanov, I. I., Lamichhane, A., et al. (2014). Innate Lymphoid Cells Regulate Intestinal Epithelial Cell Glycosylation. Science 345:1254009. doi: 10.1126/science.1254009

Gradel, K. O., Nielsen, H. L., Schonheyder, H. C., Ejlertsen, T., Kristensen, B., and Nielsen, H. (2009). Increased Short- and Long-Term Risk of Inflammatory Bowel Disease After Salmonella or Campylobacter Gastroenteritis. Gastroenterology 137, 495-501. doi: 10.1053/j.gastro.2009.04.001

Halim, T. Y., Krauss, R. H., Sun, A. C., and Takei, F. (2012). Lung Natural Helper Cells are a Critical Source of Th2 Cell-Type Cytokines in Protease AllergenInduced Airway Inflammation. Immunity 36, 451-463. doi: 10.1016/ j.immuni.2011.12.020

Hameed, A. (2019). Human Immunity Against Campylobacter Infection. Immune Netw. 19, e38. doi: 10.4110/in.2019.19.e38

Handley, S. A., Newberry, R. D., and Miller, V. L. (2005). Yersinia Enterocolitica Invasin-Dependent and Invasin-Independent Mechanisms of Systemic Dissemination. Infect. Immun. 73, 8453-8455. doi: 10.1128/iai.73.12.84538455.2005

Heimesaat, M. M., Grundmann, U., Alutis, M. E., Fischer, A., Gobel, U. B., and Bereswill, S. (2016). The Il-23/Il-22/Il-18 Axis in Murine Campylobacter Jejuni Infection. Gut Pathog. 8, 21. doi: 10.1186/s13099-016-0106-4

Hepworth, M. R., Fung, T. C., Masur, S. H., Kelsen, J. R., McConnell, F. M., Dubrot, J., et al. (2015). Immune Tolerance. Group 3 Innate Lymphoid Cells Mediate Intestinal Selection of Commensal Bacteria-Specific Cd4(+) T Cells. Science 348, 1031-1035. doi: 10.1126/science.aaa4812

Hepworth, M. R., Monticelli, L. A., Fung, T. C., Ziegler, C. G., Grunberg, S., Sinha, R., et al. (2013). Innate Lymphoid Cells Regulate Cd4+ T-Cell Responses to Intestinal Commensal Bacteria. Nature 498, 113-117. doi: 10.1038/ nature 12240

Hering, N. A., Richter, J. F., Krug, S. M., Günzel, D., Fromm, A., Bohn, E., et al. (2011). Yersinia Enterocolitica Induces Epithelial Barrier Dysfunction Through Regional Tight Junction Changes in Colonic Ht-29/B6 Cell Monolayers. Lab. Invest. J. Tech. Methods Pathol. 91, 310-324. doi: 10.1038/labinvest.2010.180

He, Y., Xu, H., Song, C., Koprivsek, J. J., Arulanandam, B., Yang, H., et al. (2021). Adoptive Transfer of Group 3-Like Innate Lymphoid Cells Restores Mouse Colon Resistance to Colonization of a Gamma Interferon-Susceptible Chlamydia Muridarum Mutant. Infect. Immun. 89 (2), e00533-00520. doi: 10.1128/IAI.00533-20 
Ho, J., Bailey, M., Zaunders, J., Mrad, N., Sacks, R., Sewell, W., et al. (2015). Group 2 Innate Lymphoid Cells (Ilc2s) are Increased in Chronic Rhinosinusitis With Nasal Polyps or Eosinophilia. Clin. Exp. Allergy J. Br. Soc. Allergy Clin. Immunol. 45, 394-403. doi: 10.1111/cea.12462

Howard, E., Lewis, G., Galle-Treger, L., Hurrell, B. P., Helou, D. G., Shafiei-Jahani, P., et al. (2021). Il-10 Production by Ilc2s Requires Blimp-1 and Cmaf, Modulates Cellular Metabolism, and Ameliorates Airway Hyperreactivity. J. Allergy Clin. Immunol. 147, 1281-95.e5. doi: 10.1016/j.jaci.2020.08.024

Howe, S. E., Shillova, N., and Konjufca, V. (2019). Dissemination of Chlamydia From the Reproductive Tract to the Gastro-Intestinal Tract Occurs in Stages and Relies on Chlamydia Transport by Host Cells. PloS Pathog. 15, e1008207. doi: 10.1371/journal.ppat.1008207

Huang, Y., Guo, L., Qiu, J., Chen, X., Hu-Li, J., Siebenlist, U., et al. (2015). Il-25Responsive, Lineage-Negative $\mathrm{Klrg} 1(\mathrm{Hi})$ Cells are Multipotential 'Inflammatory' Type 2 Innate Lymphoid Cells. Nat. Immunol. 16, 161-169. doi: $10.1038 /$ ni.3078

Huang, J., Lee, H. Y., Zhao, X., Han, J., Su, Y., Sun, Q., et al. (2021). Interleukin17d Regulates Group 3 Innate Lymphoid Cell Function Through its Receptor Cd93. Immunity 54, 673-686.e4. doi: 10.1016/j.immuni.2021.03.018

Huang, Y., Mao, K., Chen, X., Sun, M. A., Kawabe, T., Li, W., et al. (2018). S1pDependent Interorgan Trafficking of Group 2 Innate Lymphoid Cells Supports Host Defense. Science 359, 114-119. doi: 10.1126/science.aam5809

Huang, Y., and Paul, W. E. (2016). Inflammatory Group 2 Innate Lymphoid Cells. Int. Immunol. 28, 23-28. doi: 10.1093/intimm/dxv044

Ibiza, S., García-Cassani, B., Ribeiro, H., Carvalho, T., Almeida, L., Marques, R., et al. (2016). Glial-Cell-Derived Neuroregulators Control Type 3 Innate Lymphoid Cells and Gut Defence. Nature 535, 440-443. doi: 10.1038/ nature18644

Igietseme, J. U., Portis, J. L., and Perry, L. L. (2001). Inflammation and Clearance of Chlamydia Trachomatis in Enteric and Nonenteric Mucosae. Infect. Immun. 69, 1832-1840. doi: 10.1128/IAI.69.3.1832-1840.2001

Imai, Y., Yasuda, K., Nagai, M., Kusakabe, M., Kubo, M., Nakanishi, K., et al. (2019). Il-33-Induced Atopic Dermatitis-Like Inflammation in Mice is Mediated by Group 2 Innate Lymphoid Cells in Concert With Basophils. J. Invest. Dermatol. 139, 2185-2194.e3. doi: 10.1016/j.jid.2019.04.016

Ivanova, D. L., Krempels, R., Denton, S. L., Fettel, K. D., Saltz, G. M., Rach, D., et al. (2020). Nk Cells Negatively Regulate Cd8 T Cells to Promote Immune Exhaustion and Chronic Toxoplasma Gondii Infection. Front. Cell Infect. Microbiol. 10, 313. doi: 10.3389/fcimb.2020.00313

Ivashkiv, L. B. (2018). Ifngamma: Signalling, Epigenetics and Roles in Immunity, Metabolism, Disease and Cancer Immunotherapy. Nat. Rev. Immunol. 18, 545-558. doi: 10.1038/s41577-018-0029-z

Jing, X., Korchagina, A. A., Shein, S. A., Muraoka, W. T., Koroleva, E., and Tumanov, A. V. (2020). Il-23 Contributes to Campylobacter Jejuni-Induced Intestinal Pathology via Promoting Il-17 and Ifngamma Responses by Innate Lymphoid Cells. Front. Immunol. 11, 579615. doi: 10.3389/fimmu.2020.579615

Johansson, M., Schön, K., Ward, M., and Lycke, N. (1997). Genital Tract Infection With Chlamydia Trachomatis Fails to Induce Protective Immunity in Gamma Interferon Receptor-Deficient Mice Despite a Strong Local Immunoglobulin a Response. Infect. Immun. 65, 1032-1044. doi: 10.1128/iai.65.3.1032-1044.1997

Kaakoush, N. O., Castaño-Rodríguez, N., Mitchell, H. M., and Man, S. M. (2015). Global Epidemiology of Campylobacter Infection. Clin. Microbiol. Rev. 28, 687-720. doi: 10.1128/cmr.00006-15

Kak, G., Raza, M., and Tiwari, B. K. (2018). Interferon-Gamma (Ifn- $\gamma$ ): Exploring its Implications in Infectious Diseases. Biomol. Concepts 9, 64-79. doi: 10.1515/ bmc-2018-0007

Kastele, V., Mayer, J., Lee, E. S., Papazian, N., Cole, J. J., Cerovic, V., et al. (2021). Intestinal-Derived Ilcs Migrating in Lymph Increase Ifngamma Production in Response to Salmonella Typhimurium Infection. Mucosal Immunol. 14, 717727. doi: $10.1038 / \mathrm{s} 41385-020-00366-3$

Kim, B. S., Siracusa, M. C., Saenz, S. A., Noti, M., Monticelli, L. A., Sonnenberg, G. F., et al. (2013). Tslp Elicits Il-33-Independent Innate Lymphoid Cell Responses to Promote Skin Inflammation. Sci. Trans. Med. 5, 170ra16. doi: $10.1126 /$ scitranslmed.3005374

Kim, T. J., Upadhyay, V., Kumar, V., Lee, K. M., and Fu, Y. X. (2014). Innate Lymphoid Cells Facilitate Nk Cell Development Through a LymphotoxinMediated Stromal Microenvironment. J. Exp. Med. 211, 1421-1431. doi: $10.1084 /$ jem.20131501
Kiss, E. A., and Diefenbach, A. (2012). Role of the Aryl Hydrocarbon Receptor in Controlling Maintenance and Functional Programs of Rorgammat(+) Innate Lymphoid Cells and Intraepithelial Lymphocytes. Front. Immunol. 3, 124. doi: 10.3389/fimmu.2012.00124

Klose, C. S. N., Flach, M., Mohle, L., Rogell, L., Hoyler, T., Ebert, K., et al. (2014). Differentiation of Type 1 Ilcs From a Common Progenitor to All Helper-Like Innate Lymphoid Cell Lineages. Cell 157, 340-356. doi: 10.1016/ j.cell.2014.03.030

Klose, C. S., Kiss, E. A., Schwierzeck, V., Ebert, K., Hoyler, T., d'Hargues, Y., et al. (2013). A T-Bet Gradient Controls the Fate and Function of Ccr6-Rorgammat + Innate Lymphoid Cells. Nature 494, 261-265. doi: 10.1038/nature11813

Klose, C. S. N., Mahlakõiv, T., Moeller, J. B., Rankin, L. C., Flamar, A. L., Kabata, H., et al. (2017). The Neuropeptide Neuromedin U Stimulates Innate Lymphoid Cells and Type 2 Inflammation. Nature 549, 282-286. doi: 10.1038/nature23676

Konradt, C., Ueno, N., Christian, D. A., Delong, J. H., Pritchard, G. H., Herz, J., et al. (2016). Endothelial Cells are a Replicative Niche for Entry of Toxoplasma Gondii to the Central Nervous System. Nat. Microbiol. 1, 16001. doi: 10.1038/ nmicrobiol.2016.1

Koprivsek, J. J., He, Y., Song, C., Zhang, N., Tumanov, A., and Zhong, G. (2020). Evasion of Innate Lymphoid Cell-Regulated Gamma Interferon Responses by Chlamydia Muridarum to Achieve Long-Lasting Colonization in Mouse Colon. Infect. Immun. 88 (3), e00798-00719. doi: 10.1128/IAI.00798-19

Kruglov, A. A., Grivennikov, S. I., Kuprash, D. V., Winsauer, C., Prepens, S., Seleznik, G. M., et al. (2013). Nonredundant Function of Soluble Lt $\alpha 3$ Produced by Innate Lymphoid Cells in Intestinal Homeostasis. Science 342, 1243-1246. doi: 10.1126/science. 1243364

Kullberg, M. C., Jankovic, D., Feng, C. G., Hue, S., Gorelick, P. L., McKenzie, B. S., et al. (2006). Il-23 Plays a Key Role in Helicobacter Hepaticus-Induced T CellDependent Colitis. J. Exp. Med. 203, 2485-2494. doi: 10.1084/jem.20061082

Kupz, A., Scott, T. A., Belz, G. T., Andrews, D. M., Greyer, M., Lew, A. M., et al. (2013). Contribution of Thy $1+$ Nk Cells to Protective Ifn- $\gamma$ Production During Salmonella Typhimurium Infections. Proc. Natl. Acad. Sci. U.S.A. 110, 22522257. doi: 10.1073/pnas.1222047110

Kwong, B., Rua, R., Gao, Y., Flickinger, J.Jr., Wang, Y., Kruhlak, M. J., et al. (2017). T-Bet-Dependent Nkp46(+) Innate Lymphoid Cells Regulate the Onset of T (H)17-Induced Neuroinflammation. Nat. Immunol. 18, 1117-1127. doi: $10.1038 /$ ni.3816

Lei, L., Chen, J., Hou, S., Ding, Y., Yang, Z., Zeng, H., et al. (2014). Reduced Live Organism Recovery and Lack of Hydrosalpinx in Mice Infected With PlasmidFree Chlamydia Muridarum. Infect. Immun. 82, 983-992. doi: 10.1128/ IAI.01543-13

Leon-Sicairos, N., Reyes-Cortes, R., Guadron-Llanos, A. M., Maduena-Molina, J., Leon-Sicairos, C., and Canizalez-Roman, A. (2015). Strategies of Intracellular Pathogens for Obtaining Iron From the Environment. BioMed. Res. Int. 2015, 476534. doi: $10.1155 / 2015 / 476534$

Lieberman, L. A., Cardillo, F., Owyang, A. M., Rennick, D. M., Cua, D. J., Kastelein, R. A., et al. (2004). Il-23 Provides a Limited Mechanism of Resistance to Acute Toxoplasmosis in the Absence of Il-12. J. Immunol. 173, 1887-1893. doi: 10.4049/jimmunol.173.3.1887

Lim, A. I., Menegatti, S., Bustamante, J., Le Bourhis, L., Allez, M., Rogge, L., et al. (2016). Il-12 Drives Functional Plasticity of Human Group 2 Innate Lymphoid Cells. J. Exp. Med. 213, 569-583. doi: 10.1084/jem.20151750

Lippert, E., Karrasch, T., Sun, X., Allard, B., Herfarth, H. H., Threadgill, D., et al. (2009). Gnotobiotic Il-10; Nf-Kappab Mice Develop Rapid and Severe Colitis Following Campylobacter Jejuni Infection. PloS One 4, e7413. doi: 10.1371/ journal.pone.0007413

Lopez-Yglesias, A. H., Burger, E., Camanzo, E., Martin, A. T., Araujo, A. M., Kwok, S. F., et al. (2021). T-Bet-Dependent Ilc1- and Nk Cell-Derived IfnGamma Mediates Cdc1-Dependent Host Resistance Against Toxoplasma Gondii. PloS Pathog. 17, e1008299. doi: 10.1371/journal.ppat.1008299

Lu, G., Zhang, R., Geng, S., Peng, L., Jayaraman, P., Chen, C., et al. (2015). Myeloid Cell-Derived Inducible Nitric Oxide Synthase Suppresses M1 Macrophage Polarization. Nat. Commun. 6, 6676. doi: 10.1038/ncomms7676

Macho-Fernandez, E., Koroleva, E. P., Spencer, C. M., Tighe, M., Torrado, E. Cooper, A. M., et al. (2015). Lymphotoxin Beta Receptor Signaling Limits Mucosal Damage Through Driving Il-23 Production by Epithelial Cells. Mucosal Immunol. 8, 403-413. doi: 10.1038/mi.2014.78 
Maggi, L., Montaini, G., Mazzoni, A., Rossettini, B., Capone, M., Rossi, M. C., et al. (2017). Human Circulating Group 2 Innate Lymphoid Cells can Express Cd154 and Promote Ige Production. J. Allergy Clin. Immunol. 139, 96476.e4. doi: 10.1016/j.jaci.2016.06.032

Malik, A., Sharma, D., St Charles, J., Dybas, L. A., and Mansfield, L. S. (2014). Contrasting Immune Responses Mediate Campylobacter Jejuni-Induced Colitis and Autoimmunity. Mucosal Immunol. 7, 802-817. doi: 10.1038/ mi.2013.97

Man, S. M. (2011). The Clinical Importance of Emerging Campylobacter Species. Nature Reviews. Gastroenterol. Hepatol. 8, 669-685. doi: 10.1038/ nrgastro.2011.191

Mansfield, L. S., Bell, J. A., Wilson, D. L., Murphy, A. J., Elsheikha, H. M., Rathinam, V. A., et al. (2007). C57bl/6 and Congenic Interleukin-10-Deficient Mice can Serve as Models of Campylobacter Jejuni Colonization and Enteritis. Infect. Immun. 75, 1099-1115. doi: 10.1128/IAI.00833-06

Mansfield, L. S., Patterson, J. S., Fierro, B. R., Murphy, A. J., Rathinam, V. A., Kopper, J. J., et al. (2008). Genetic Background of Il-10(-/-) Mice Alters HostPathogen Interactions With Campylobacter Jejuni and Influences Disease Phenotype. Microb. Pathogen. 45, 241-257. doi: 10.1016/j.micpath.2008.05.010

Marin, N. D., Dunlap, M. D., Kaushal, D., and Khader, S. A. (2019). Friend or Foe: The Protective and Pathological Roles of Inducible Bronchus-Associated Lymphoid Tissue in Pulmonary Diseases. J. Immunol. (Baltimore Md. 1950) 202, 2519-2526. doi: 10.4049/jimmunol.1801135

Mashayekhi, M., Sandau, M. M., Dunay, I. R., Frickel, E. M., Khan, A., Goldszmid, R. S., et al. (2011). Cd $8 \alpha(+)$ Dendritic Cells are the Critical Source of Interleukin-12 That Controls Acute Infection by Toxoplasma Gondii Tachyzoites. Immunity 35, 249-259. doi: 10.1016/j.immuni.2011.08.008

May, G. R., Sutherland, L. R., and Meddings, J. B. (1993). Is Small Intestinal Permeability Really Increased in Relatives of Patients With Crohn's Disease? Gastroenterology 104, 1627-1632. doi: 10.1016/0016-5085(93)90638-s

Mazzurana, L., Bonfiglio, F., Forkel, M., D'Amato, M., Halfvarson, J., and Mjösberg, J. (2021). Crohn's Disease is Associated With Activation of Circulating Innate Lymphoid Cells. Inflamm. Bowel Dis. 27, 1128-1138. doi: 10.1093/ibd/izaa316

Mazzurana, L., Czarnewski, P., Jonsson, V., Wigge, L., Ringnér, M., Williams, T. C., et al. (2021). Tissue-Specific Transcriptional Imprinting and Heterogeneity in Human Innate Lymphoid Cells Revealed by Full-Length Single-Cell RnaSequencing. Cell Res. 31, 554-568. doi: 10.1038/s41422-020-00445-x

McCarthy, N., and Giesecke, J. (2001). Incidence of Guillain-Barre Syndrome Following Infection With Campylobacter Jejuni. Am. J. Epidemiol. 153, 610614. doi: $10.1093 /$ aje/153.6.610

McKenzie, A. N. (2014). ype-2 Innate Lymphoid Cells in Asthma and Allergy. Ann. Am. Thorac. Soc. 11 (Suppl 5), S263-S270. doi: 10.1513/ AnnalsATS.201403-097AW

Mebius, R. E., Rennert, P., and Weissman, I. L. (1997). Developing Lymph Nodes Collect Cd4+Cd3- Ltbeta+ Cells That can Differentiate to Apc, Nk Cells, and Follicular Cells But Not T or B Cells. Immunity 7, 493-504. doi: 10.1016/s10747613(00)80371-4

Melo-Gonzalez, F., and Hepworth, M. R. (2017). Functional and Phenotypic Heterogeneity of Group 3 Innate Lymphoid Cells. Immunology 150, 265-275. doi: $10.1111 /$ imm.12697

Mercado, M. A. B., Du, W., Malaviarachchi, P. A., Gann, J. I., and Li, L. X. (2021). Innate Ifn-Gamma is Essential for Systemic Chlamydia Muridarum Control in Mice, While Cd4 T Cell-Dependent Ifn-Gamma Production is Highly Redundant in the Female Reproductive Tract. Infect. Immun. 89(3), e0054100520. doi: 10.1128/IAI.00541-20

Metzemaekers, M., Vanheule, V., Janssens, R., Struyf, S., and Proost, P. (2017). Overview of the Mechanisms That may Contribute to the non-Redundant Activities of Interferon-Inducible Cxc Chemokine Receptor 3 Ligands. Front. Immunol. 8, 1970. doi: 10.3389/fimmu.2017.01970

Mikami, Y., Scarno, G., Zitti, B., Shih, H. Y., Kanno, Y., Santoni, A., et al. (2018). $\mathrm{Ncr}(+)$ Ilc3 Maintain Larger Stat4 Reservoir via T-Bet to Regulate Type 1 Features Upon Il-23 Stimulation in Mice. Eur. J. Immunol. 48, 1174-1180. doi: $10.1002 /$ eji.201847480

Mjosberg, J., Bernink, J., Golebski, K., Karrich, J. J., Peters, C. P., Blom, B., et al. (2012). The Transcription Factor Gata3 is Essential for the Function of Human Type 2 Innate Lymphoid Cells. Immunity 37, 649-659. doi: 10.1016/ j.immuni.2012.08.015
Mjösberg, J. M., Trifari, S., Crellin, N. K., Peters, C. P., van Drunen, C. M., Piet, B., et al. (2011). Human Il-25- and Il-33-Responsive Type 2 Innate Lymphoid Cells are Defined by Expression of Crth2 and Cd161. Nat. Immunol. 12, 10551062. doi: $10.1038 /$ ni.2104

Mortha, A., Chudnovskiy, A., Hashimoto, D., Bogunovic, M., Spencer, S. P., Belkaid, Y., et al. (2014). Microbiota-Dependent Crosstalk Between Macrophages and Ilc3 Promotes Intestinal Homeostasis. Science 343, 1249288. doi: $10.1126 /$ science. 1249288

Munoz, M., Eidenschenk, C., Ota, N., Wong, K., Lohmann, U., Kuhl, A. A., et al. (2015). Interleukin-22 Induces Interleukin-18 Expression From Epithelial Cells During Intestinal Infection. Immunity 42, 321-331. doi: 10.1016/ j.immuni.2015.01.011

Munoz, M., Heimesaat, M. M., Danker, K., Struck, D., Lohmann, U., Plickert, R., et al. (2009). Interleukin (Il)-23 Mediates Toxoplasma Gondii-Induced Immunopathology in the Gut via Matrixmetalloproteinase-2 and Il-22 But Independent of Il-17. J. Exp. Med. 206, 3047-3059. doi: 10.1084/ jem. 20090900

Munoz, M., Liesenfeld, O., and Heimesaat, M. M. (2011). Immunology of Toxoplasma Gondii. Immunol. Rev. 240, 269-285. doi: 10.1111/j.1600065X.2010.00992.X

Muraoka, W. T., Korchagina, A. A., Xia, Q., Shein, S. A., Jing, X., Lai, Z., et al. (2021). Campylobacter Infection Promotes Ifngamma-Dependent Intestinal Pathology via Ilc3 to Ilc1 Conversion. Mucosal Immunol. 14, 703-716. doi: 10.1038/s41385-020-00353-8

Nachamkin, I. (2002). Chronic Effects of Campylobacter Infection. Microbes Infect. 4, 399-403. doi: 10.1016/s1286-4579(02)01553-8

Nagashima, H., Mahlakõiv, T., Shih, H. Y., Davis, F. P., Meylan, F., Huang, Y., et al. (2019). Neuropeptide Cgrp Limits Group 2 Innate Lymphoid Cell Responses and Constrains Type 2 Inflammation. Immunity 51, 682-695.e6. doi: 10.1016/ j.immuni.2019.06.009

Nava, P., Koch, S., Laukoetter, M. G., Lee, W. Y., Kolegraff, K., Capaldo, C. T., et al. (2010). Interferon-Gamma Regulates Intestinal Epithelial Homeostasis Through Converging Beta-Catenin Signaling Pathways. Immunity 32, 392402. doi: 10.1016/j.immuni.2010.03.001

Navarro-Llavat, M., Domenech, E., Bernal, I., Sanchez-Delgado, J., Manterola, J. M., Garcia-Planella, E., et al. (2009). Prospective, Observational, CrossSectional Study of Intestinal Infections Among Acutely Active Inflammatory Bowel Disease Patients. Digestion 80, 25-29. doi: 10.1159/000212076

Neill, D. R., Wong, S. H., Bellosi, A., Flynn, R. J., Daly, M., Langford, T. K., et al. (2010). Nuocytes Represent a New Innate Effector Leukocyte That Mediates Type-2 Immunity. Nature 464, 1367-1370. doi: 10.1038/nature08900

Ngo Thi Phuong, N., Palmieri, V., Adamczyk, A., Klopfleisch, R., Langhorst, J., Hansen, W., et al. (2021). Il-33 Drives Expansion of Type 2 Innate Lymphoid Cells and Regulatory T Cells and Protects Mice From Severe, Acute Colitis. Front. Immunol. 12:669787. doi: 10.3389/fimmu.2021.669787

Odenwald, M. A., and Turner, J. R. (2017). The Intestinal Epithelial Barrier: A Therapeutic Target? Nature Reviews. Gastroenterol. Hepatol. 14, 9-21. doi: 10.1038/nrgastro.2016.169

Okamura, H., Kashiwamura, S., Tsutsui, H., Yoshimoto, T., and Nakanishi, K. (1998). Regulation of Interferon-Gamma Production by Il-12 and Il-18. Curr. Opin. Immunol. 10, 259-264. doi: 10.1016/s0952-7915(98)80163-5

Onder, L., and Ludewig, B. (2018). A Fresh View on Lymph Node Organogenesis. Trends Immunol. 39, 775-787. doi: 10.1016/j.it.2018.08.003

Pahari, S., Khan, N., Aqdas, M., Negi, S., Kaur, J., and Agrewala, J. N. (2016). Infergen Stimulated Macrophages Restrict Mycobacterium Tuberculosis Growth by Autophagy and Release of Nitric Oxide. Sci. Rep. 6, 39492. doi: $10.1038 /$ srep 39492

Palm, N. W., Rosenstein, R. K., and Medzhitov, R. (2012). Allergic Host Defences. Nature 484, 465-472. doi: 10.1038/nature1 1047

Pan, L., Chen, X., Liu, X., Qiu, W., Liu, Y., Jiang, W., et al. (2021). Innate Lymphoid Cells Exhibited Il-17-Expressing Phenotype in Active Tuberculosis Disease. BMC Pulmon. Med. 21, 318. doi: 10.1186/s12890-021-01678-1

Pappu, R., Rutz, S., and Ouyang, W. (2012). Regulation of Epithelial Immunity by Il-17 Family Cytokines. Trends Immunol. 33, 343-349. doi: 10.1016/ j.it.2012.02.008

Park, E., Patel, S., Wang, Q., Andhey, P., Zaitsev, K., Porter, S., et al. (2019). Toxoplasma Gondii Infection Drives Conversion of Nk Cells Into Ilc1-Like Cells. eLife 8, e47605. doi: 10.7554/eLife.47605 
Perry, L. L., Feilzer, K., and Caldwell, H. D. (1997). Immunity to Chlamydia Trachomatis is Mediated by T Helper 1 Cells Through Ifn-Gamma-Dependent and -Independent Pathways. J. Immunol. 158 (7), 3344-3352.

Pham, O. H., and McSorley, S. J. (2015). Protective Host Immune Responses to Salmonella Infection. Future Microbiol. 10, 101-110. doi: 10.2217/fmb.14.98

Podinovskaia, M., Lee, W., Caldwell, S., and Russell, D. G. (2013). Infection of Macrophages With Mycobacterium Tuberculosis Induces Global Modifications to Phagosomal Function. Cell. Microbiol. 15, 843-859. doi: $10.1111 / \mathrm{cmi} .12092$

Popov, A., Abdullah, Z., Wickenhauser, C., Saric, T., Driesen, J., Hanisch, F. G., et al. (2006). Indoleamine 2,3-Dioxygenase-Expressing Dendritic Cells Form Suppurative Granulomas Following Listeria Monocytogenes Infection. J. Clin. Invest. 116, 3160-3170. doi: 10.1172/JCI28996

Price, A. E., Liang, H. E., Sullivan, B. M., Reinhardt, R. L., Eisley, C. J., Erle, D. J., et al. (2010). Systemically Dispersed Innate Il-13-Expressing Cells in Type 2 Immunity. Proc. Natl. Acad. Sci. U.S.A. 107, 11489-11494. doi: 10.1073/ pnas. 1003988107

Pu, Q., Lin, P., Gao, P., Wang, Z., Guo, K., Qin, S., et al. (2021). Gut Microbiota Regulate Gut-Lung Axis Inflammatory Responses by Mediating Ilc2 Compartmental Migration. J. Immunol. doi: 10.4049/jimmunol.2001304

Qiu, J., Heller, J. J., Guo, X., Chen, Z. M., Fish, K., Fu, Y. X., et al. (2012). The Aryl Hydrocarbon Receptor Regulates Gut Immunity Through Modulation of Innate Lymphoid Cells. Immunity 36, 92-104. doi: 10.1016/ j.immuni.2011.11.011

Rank, R. G., and Yeruva, L. (2014). Hidden in Plain Sight: Chlamydial Gastrointestinal Infection and its Relevance to Persistence in Human Genital Infection. Infect. Immun. 82, 1362-1371. doi: 10.1128/iai.01244-13

Rao, A., Strauss, O., Kokkinou, E., Bruchard, M., Tripathi, K. P., Schlums, H., et al. (2020). Cytokines Regulate the Antigen-Presenting Characteristics of Human Circulating and Tissue-Resident Intestinal Ilcs. Nat. Commun. 11, 2049. doi: 10.1038/s41467-020-15695-x

Reynders, A., Yessaad, N., Vu Manh, T. P., Dalod, M., Fenis, A., Aubry, C., et al. (2011). Identity, Regulation and In Vivo Function of Gut Nkp46+Rorgammat+ and Nkp46+Rorgammat- Lymphoid Cells. EMBO J. 30, 2934-2947. doi: $10.1038 /$ emboj.2011.201

Robinette, M. L., Cella, M., Telliez, J. B., Ulland, T. K., Barrow, A. D., Capuder, K., et al. (2018). Jak3 Deficiency Blocks Innate Lymphoid Cell Development. Mucosal Immunol. 11, 50-60. doi: 10.1038/mi.2017.38

Romero-Suárez, S., Del Rio Serrato, A., Bueno, R. J., Brunotte-Strecker, D., Stehle, C., Figueiredo, C. A., et al. (2019). The Central Nervous System Contains Ilc1s That Differ From Nk Cells in the Response to Inflammation. Front. Immunol. 10, 2337. doi: 10.3389/fimmu.2019.02337

Rottenberg, M. E., Gigliotti Rothfuchs, A., Gigliotti, D., Ceausu, M., Une, C., Levitsky, V., et al. (2000). Regulation and Role of Ifn-Gamma in the Innate Resistance to Infection With Chlamydia Pneumoniae. J. Immunol. (Baltimore Md. 1950) 164, 4812-4818. doi: 10.4049/jimmunol.164.9.4812

Rottenberg, M. E., Gigliotti-Rothfuchs, A., and Wigzell, H. (2002). The Role of IfnGamma in the Outcome of Chlamydial Infection. Curr. Opin. Immunol. 14, 444-451. doi: 10.1016/s0952-7915(02)00361-8

Salimi, M., Barlow, J. L., Saunders, S. P., Xue, L., Gutowska-Owsiak, D., Wang, X., et al. (2013). A Role for Il-25 and Il-33-Driven Type-2 Innate Lymphoid Cells in Atopic Dermatitis. J. Exp. Med. 210, 2939-2950. doi: 10.1084/jem.20130351

Sanos, S. L., Bui, V. L., Mortha, A., Oberle, K., Heners, C., Johner, C., et al. (2009). Rorgammat and Commensal Microflora are Required for the Differentiation of Mucosal Interleukin 22-Producing Nkp46+ Cells. Nat. Immunol. 10, 83-91. doi: $10.1038 /$ ni. 1684

Santos, R. L., and Bäumler, A. J. (2004). Cell Tropism of Salmonella Enterica. Int. J. Med. Microbiol. IJMM 294, 225-233. doi: 10.1016/j.ijmm.2004.06.029

Satoh-Takayama, N., Kato, T., Motomura, Y., Kageyama, T., Taguchi-Atarashi, N., Kinoshita-Daitoku, R., et al. (2020). Bacteria-Induced Group 2 Innate Lymphoid Cells in the Stomach Provide Immune Protection Through Induction of Iga. Immunity 52, 635-649.e4. doi: 10.1016/j.immuni.2020.03.002

Scandella, E., Bolinger, B., Lattmann, E., Miller, S., Favre, S., Littman, D. R., et al. (2008). Restoration of Lymphoid Organ Integrity Through the Interaction of Lymphoid Tissue-Inducer Cells With Stroma of the T Cell Zone. Nat. Immunol. 9, 667-675. doi: 10.1038/ni.1605

Scharton-Kersten, T. M., Wynn, T. A., Denkers, E. Y., Bala, S., Grunvald, E., Hieny, S., et al. (1996). In the Absence of Endogenous Ifn-Gamma, Mice
Develop Unimpaired Il-12 Responses to Toxoplasma Gondii While Failing to Control Acute Infection. J. Immunol. 157(9), 4045-4054.

Schmitz, H., Barmeyer, C., Fromm, M., Runkel, N., Foss, H. D., Bentzel, C. J., et al. (1999). Altered Tight Junction Structure Contributes to the Impaired Epithelial Barrier Function in Ulcerative Colitis. Gastroenterology 116, 301-309. doi: 10.1016/s0016-5085(99)70126-5

Schroder, K., Hertzog, P. J., Ravasi, T., and Hume, D. A. (2004). InterferonGamma: An Overview of Signals, Mechanisms and Functions. J. Leukoc. Biol. 75, 163-189. doi: 10.1189/jlb.0603252

Schwartz, D. M., Kanno, Y., Villarino, A., Ward, M., Gadina, M., and O'Shea, J. J. (2017). Jak Inhibition as a Therapeutic Strategy for Immune and Inflammatory Diseases. Nat. Rev. Drug Discov 17, 78. doi: 10.1038/nrd.2017.267

Seehus, C. R., Kadavallore, A., Torre, B., Yeckes, A. R., Wang, Y., Tang, J., et al. (2017). Alternative Activation Generates Il-10 Producing Type 2 Innate Lymphoid Cells. Nat. Commun. 8, 1900. doi: 10.1038/s41467-017-02023-z

Seillet, C., Luong, K., Tellier, J., Jacquelot, N., Shen, R. D., Hickey, P., et al. (2020). The Neuropeptide Vip Confers Anticipatory Mucosal Immunity by Regulating Ilc3 Activity. Nat. Immunol. 21, 168-177. doi: 10.1038/s41590-019-0567-y

Seo, G. Y., Giles, D. A., and Kronenberg, M. (2020). The Role of Innate Lymphoid Cells in Response to Microbes at Mucosal Surfaces. Mucosal Immunol. 13, 399412. doi: 10.1038/s41385-020-0265-y

Seo, G. Y., Shui, J. W., Takahashi, D., Song, C., Wang, Q., Kim, K., et al. (2018). Light-Hvem Signaling in Innate Lymphoid Cell Subsets Protects Against Enteric Bacterial Infection. Cell Host Microbe 24, 249-60.e4. doi: 10.1016/ j.chom.2018.07.008

Shou, Y., Koroleva, E., Spencer, C. M., Shein, S. A., Korchagina, A. A., Yusoof, K. A., et al. (2021). Redefining the Role of Lymphotoxin Beta Receptor in the Maintenance of Lymphoid Organs and Immune Cell Homeostasis in Adulthood. Front. Immunol. 12, 712632. doi: 10.3389/fimmu.2021.712632

Shtrichman, R., and Samuel, C. E. (2001). The Role of Gamma Interferon in Antimicrobial Immunity. Curr. Opin. Microbiol. 4, 251-259. doi: 10.1016/ s1369-5274(00)00199-5

Silver, J. S., Kearley, J., Copenhaver, A. M., Sanden, C., Mori, M., Yu, L., et al. (2016). Inflammatory Triggers Associated With Exacerbations of Copd Orchestrate Plasticity of Group 2 Innate Lymphoid Cells in the Lungs. Nat. Immunol. 17, 626-635. doi: 10.1038/ni.3443

Simic, M., Manosalva, I., Spinelli, L., Gentek, R., Shayan, R. R., Siret, C., et al. (2020). Distinct Waves From the Hemogenic Endothelium Give Rise to Layered Lymphoid Tissue Inducer Cell Ontogeny. Cell Rep. 32, 108004. doi: 10.1016/j.celrep.2020.108004

Songhet, P., Barthel, M., Stecher, B., Muller, A. J., Kremer, M., Hansson, G. C., et al. (2011). Stromal Ifn-Gammar-Signaling Modulates Goblet Cell Function During Salmonella Typhimurium Infection. PloS One 6, e22459. doi: 10.1371/ journal.pone.0022459

Stabile, H., Scarno, G., Fionda, C., Gismondi, A., Santoni, A., Gadina, M., et al. (2018). Jak/stat Signaling in Regulation of Innate Lymphoid Cells: The Gods Before the Guardians. Immunol. Rev. 286, 148-159. doi: 10.1111/imr.12705

Steigler, P., Daniels, N. J., McCulloch, T. R., Ryder, B. M., Sandford, S. K., and Kirman, J. R. (2018). Bcg Vaccination Drives Accumulation and Effector Function of Innate Lymphoid Cells in Murine Lungs. Immunol. Cell Biol. 96 , 379-389. doi: 10.1111/imcb.12007

Steimle, V., Siegrist, C.-A., Mottet, A., Lisowska-Grospierre, B., and Mach, B. (1994). Regulation of Mhc Class Ii Expression by Interferon-\&\#X3b3; Mediated by the Transactivator Gene Ciita. Science 265, 106-109. doi: $10.1126 /$ science. 8016643

Sun, X., Threadgill, D., and Jobin, C. (2012). Campylobacter Jejuni Induces Colitis Through Activation of Mammalian Target of Rapamycin Signaling. Gastroenterology 142, 86-95.e5. doi: 10.1053/j.gastro.2011.09.042

Suzuki, Y., Orellana, M. A., Schreiber, R. D., and Remington, J. S. (1988). Interferon-Gamma: The Major Mediator of Resistance Against Toxoplasma Gondii. Science 240, 516-518. doi: 10.1126/science. 3128869

Tahoun, A., Mahajan, S., Paxton, E., Malterer, G., Donaldson, D. S., Wang, D., et al. (2012). Salmonella Transforms Follicle-Associated Epithelial Cells Into M Cells to Promote Intestinal Invasion. Cell Host Microbe 12, 645-656. doi: 10.1016/j.chom.2012.10.009

Tait Wojno, E. D., Hunter, C. A., and Stumhofer, J. S. (2019). The Immunobiology of the Interleukin-12 Family: Room for Discovery. Immunity 50, 851-870. doi: 10.1016/j.immuni.2019.03.011 
Takayama, T., Kamada, N., Chinen, H., Okamoto, S., Kitazume, M. T., Chang, J., et al. (2010). Imbalance of Nkp44(+)Nkp46(-) and Nkp44(-)Nkp46(+) Natural Killer Cells in the Intestinal Mucosa of Patients With Crohn's Disease. Gastroenterology 139, 882-92, 92.e1-3. doi: 10.1053/j.gastro.2010.05.040

Talbot, J., Hahn, P., Kroehling, L., Nguyen, H., Li, D., and Littman, D. R. (2020). Feeding-Dependent Vip Neuron-Ilc3 Circuit Regulates the Intestinal Barrier. Nature 579, 575-580. doi: 10.1038/s41586-020-2039-9

Tang, L., Zhang, H., Lei, L., Gong, S., Zhou, Z., Baseman, J., et al. (2013). Oviduct Infection and Hydrosalpinx in Dba1/J Mice is Induced by Intracervical But Not Intravaginal Inoculation With Chlamydia Muridarum. PloS One 8, e71649. doi: 10.1371/journal.pone.0071649

Thakur, A., Mikkelsen, H., and Jungersen, G. (2019). Intracellular Pathogens: Host Immunity and Microbial Persistence Strategies. J. Immunol. Res. 2019:1356540. doi: $10.1155 / 2019 / 1356540$

Tian, Q., Zhou, Z., Wang, L., Abu-Khdeir, A. H., Huo, Z., Sun, X., et al. (2020). Gastrointestinal Coinfection Promotes Chlamydial Pathogenicity in the Genital Tract. Infect. Immun. 88 (4), e00905-00919. doi: 10.1128/iai.00905-19

Tominaga, K., Yoshimoto, T., Torigoe, K., Kurimoto, M., Matsui, K., Hada, T., et al. (2000). Il-12 Synergizes With Il-18 or Il- $1 \beta$ for Ifn- $\gamma$ Production From Human T Cells. Int. Immunol. 12, 151-160. doi: 10.1093/intimm/12.2.151

Tribble, D. R., Baqar, S., Scott, D. A., Oplinger, M. L., Trespalacios, F., Rollins, D., et al. (2010). Assessment of the Duration of Protection in Campylobacter Jejuni Experimental Infection in Humans. Infect. Immun. 78, 1750-1759. doi: 10.1128/iai.01021-09

Tseng, C. T., and Rank, R. G. (1998). Role of Nk Cells in Early Host Response to Chlamydial Genital Infection. Infect. Immun. 66, 5867-5875. doi: 10.1128/ iai.66.12.5867-5875.1998

Tumanov, A. V., Koroleva, E. P., Guo, X., Wang, Y., Kruglov, A., Nedospasov, S., et al. (2011). Lymphotoxin Controls the Il-22 Protection Pathway in Gut Innate Lymphoid Cells During Mucosal Pathogen Challenge. Cell Host Microbe 10, 44-53. doi: 10.1016/j.chom.2011.06.002

Ulrichs, T., Kosmiadi, G. A., Trusov, V., Jorg, S., Pradl, L., Titukhina, M., et al. (2004). Human Tuberculous Granulomas Induce Peripheral Lymphoid Follicle-Like Structures to Orchestrate Local Host Defence in the Lung. J. Pathol. 204, 217-228. doi: 10.1002/path.1628

van de Pavert, S. A. (2021). Lymphoid Tissue Inducer (Lti) Cell Ontogeny and Functioning in Embryo and Adult. Biomed. J. 44, 123-132. doi: 10.1016/ j.bj.2020.12.003

van der Gracht, E., Zahner, S., and Kronenberg, M. (2016). When Insult is Added to Injury: Cross Talk Between Ilcs and Intestinal Epithelium in Ibd. Mediators Inflamm. 2016, 9765238. doi: 10.1155/2016/9765238

Vasilevsky, S., Greub, G., Nardelli-Haefliger, D., and Baud, D. (2014). Genital Chlamydia Trachomatis: Understanding the Roles of Innate and Adaptive Immunity in Vaccine Research. Clin. Microbiol. Rev. 27, 346-370. doi: 10.1128/ CMR.00105-13

Victor, A. R., Nalin, A. P., Dong, W., McClory, S., Wei, M., Mao, C., et al. (2017). Il-18 Drives Ilc3 Proliferation and Promotes Il-22 Production via Nf- $\mathrm{kb}$. J. Immunol. (Baltimore Md. 1950) 199, 2333-2342. doi: 10.4049/ jimmunol.1601554

Villanova, F., Flutter, B., Tosi, I., Grys, K., Sreeneebus, H., Perera, G. K., et al. (2014). Characterization of Innate Lymphoid Cells in Human Skin and Blood Demonstrates Increase of Nkp44+ Ilc3 in Psoriasis. J. Invest. Dermatol. 134, 984-991. doi: 10.1038/jid.2013.477

Vivier, E., Artis, D., Colonna, M., Diefenbach, A., Di Santo, J. P., Eberl, G., et al. (2018). Innate Lymphoid Cells: 10 Years on. Cell 174, 1054-1066. doi: 10.1016/ j.cell.2018.07.017

Vivier, E., Spits, H., and Cupedo, T. (2009). Interleukin-22-Producing Innate Immune Cells: New Players in Mucosal Immunity and Tissue Repair? Nat. Rev. Immunol. 9, 229-234. doi: 10.1038/nri2522

Vonarbourg, C., Mortha, A., Bui, V. L., Hernandez, P. P., Kiss, E. A., Hoyler, T., et al. (2010). Regulated Expression of Nuclear Receptor Rorgammat Confers Distinct Functional Fates to Nk Cell Receptor-Expressing Rorgammat(+) Innate Lymphocytes. Immunity 33, 736-751. doi: 10.1016/j.immuni.2010.10.017

Vossenkamper, A., Struck, D., Alvarado-Esquivel, C., Went, T., Takeda, K., Akira, S., et al. (2004). Both Il-12 and Il-18 Contribute to Small Intestinal Th1-Type Immunopathology Following Oral Infection With Toxoplasma Gondii, But Il12 is Dominant Over Il-18 in Parasite Control. Eur. J. Immunol. 34, 3197-3207. doi: $10.1002 /$ eji.200424993
Walker, J. A., and McKenzie, A. N. (2013). Development and Function of Group 2 Innate Lymphoid Cells. Curr. Opin. Immunol. 25, 148-155. doi: 10.1016/ j.coi.2013.02.010

Wallrapp, A., Riesenfeld, S. J., Burkett, P. R., Abdulnour, R. E., Nyman, J., Dionne, D., et al. (2017). The Neuropeptide Nmu Amplifies Ilc2-Driven Allergic Lung Inflammation. Nature 549, 351-356. doi: 10.1038/nature24029

Wang, X., Cai, J., Lin, B., Ma, M., Tao, Y., Zhou, Y., et al. (2021). Gpr34-Mediated Sensing of Lysophosphatidylserine Released by Apoptotic Neutrophils Activates Type 3 Innate Lymphoid Cells to Mediate Tissue Repair. Immunity 54, 1123-1136.e8. doi: 10.1016/j.immuni.2021.05.007

Wang, Y., Koroleva, E. P., Kruglov, A. A., Kuprash, D. V., Nedospasov, S. A., Fu, Y. X., et al. (2010). Lymphotoxin Beta Receptor Signaling in Intestinal Epithelial Cells Orchestrates Innate Immune Responses Against Mucosal Bacterial Infection. Immunity 32, 403-413. doi: 10.1016/j.immuni.2010.02.011

Wang, L., Zhu, C., Zhang, T., Tian, Q., Zhang, N., Morrison, S., et al. (2018). Nonpathogenic Colonization With Chlamydia in the Gastrointestinal Tract as Oral Vaccination for Inducing Transmucosal Protection. Infect. Immun. 86(2), e00630-00617. doi: 10.1128/iai.00630-17

Ward, N. L., and Umetsu, D. T. (2014). A New Player on the Psoriasis Block: Il17a- and Il-22-Producing Innate Lymphoid Cells. J. Invest. Dermatol. 134, 2305-2307. doi: 10.1038/jid.2014.216

Wassenaar, T. M., Engelskirchen, M., Park, S., and Lastovica, A. (1997). Differential Uptake and Killing Potential of Campylobacter Jejuni by Human Peripheral Monocytes/Macrophages. Med. Microbiol. Immunol. 186, 139-144. doi: $10.1007 / \mathrm{s} 004300050056$

Wilson, M. S., Feng, C. G., Barber, D. L., Yarovinsky, F., Cheever, A. W., Sher, A., et al. (2010). Redundant and Pathogenic Roles for Il-22 in Mycobacterial, Protozoan, and Helminth Infections. J. Immunol. (Baltimore Md. 1950) 184, 4378-4390. doi: 10.4049/jimmunol.0903416

Wong, S. H., Walker, J. A., Jolin, H. E., Drynan, L. F., Hams, E., Camelo, A., et al. (2012). Transcription Factor Ror $\alpha$ is Critical for Nuocyte Development. Nat. Immunol. 13, 229-236. doi: 10.1038/ni.2208

Wroblewska, J. A., Zhang, Y., Tang, H., Guo, X., Nagler, C., and Fu, Y. X. (2017). Cutting Edge: Lymphotoxin Signaling is Essential for Clearance of Salmonella From the Gut Lumen and Generation of Anti-Salmonella Protective Immunity. J. Immunol. (Baltimore Md. 1950) 198, 55-60. doi: 10.4049/jimmunol.1600867

Xaus, J., Comalada, M., Barrachina, M., Herrero, C., Goñalons, E., Soler, C., et al. (2000). The Expression of Mhc Class Ii Genes in Macrophages Is Cell Cycle Dependent. J. Immunol. 165, 6364-6371. doi: 10.4049/jimmunol.165. 11.6364

Xiao, Q., He, J., Lei, A., Xu, H., Zhang, L., Zhou, P., et al. (2021). Ppargamma Enhances Ilc2 Function During Allergic Airway Inflammation via Transcription Regulation of St2. Mucosal Immunol. 14, 468-478. doi: 10.1038/s41385-020-00339-6

Xu, H., Su, X., Zhao, Y., Tang, L., Chen, J., and Zhong, G. (2020). Innate Lymphoid Cells Are Required for Endometrial Resistance to Chlamydia Trachomatis Infection. Infect. Immun. 88(7), e00152-00120. doi: 10.1128/ IAI.00152-20

Yadav, J., Dikshit, N., Ismaeel, S., and Qadri, A. (2020). Innate Activation of Ifn- $\gamma$ Inos Axis During Infection With Salmonella Represses the Ability of T Cells to Produce Il-2. Front. Immunol. 11, 514. doi: 10.3389/fimmu.2020.00514

Yarovinsky, F. (2014). Innate Immunity to Toxoplasma Gondii Infection. Nat. Rev. Immunol. 14, 109-121. doi: 10.1038/nri3598

Yeruva, L., Spencer, N., Bowlin, A. K., Wang, Y., and Rank, R. G. (2013). Chlamydial Infection of the Gastrointestinal Tract: A Reservoir for Persistent Infection. Pathog. Dis. 68, 88-95. doi: 10.1111/2049-632X.12052

Yin, S., Yu, J., Hu, B., Lu, C., Liu, X., Gao, X., et al. (2018). Runx3 Mediates Resistance to Intracellular Bacterial Infection by Promoting Il12 Signaling in Group $1 \mathrm{Ilc}$ and Ncr+Ilc3. Front. Immunol. 9, 2101. doi: 10.3389/ fimmu.2018.02101

Young, K. T., Davis, L. M., and Dirita, V. J. (2007). Campylobacter Jejuni: Molecular Biology and Pathogenesis. Nat. Rev. Microbiol. 5, 665-679. doi: $10.1038 /$ nrmicrol718

You, Y., Zhang, X., Wang, X., Yue, D., Meng, F., Zhu, J., et al. (2020). Ilc2 Proliferated by Il-33 Stimulation Alleviates Acute Colitis in Rag1(-/-) Mouse Through Promoting M2 Macrophage Polarization. J. Immunol. Res. 2020, 5018975. doi: $10.1155 / 2020 / 5018975$ 
Yu, Q. N., Tan, W. P., Fan, X. L., Guo, Y. B., Qin, Z. L., Li, C. L., et al. (2018). Increased Group 2 Innate Lymphoid Cells Are Correlated With Eosinophilic Granulocytes in Patients With Allergic Airway Inflammation. Int. Arch. Allergy Immunol. 176, 124-132. doi: 10.1159/000488050

Zarepour, M., Bhullar, K., Montero, M., Ma, C., Huang, T., Velcich, A., et al. (2013). The Mucin Muc2 Limits Pathogen Burdens and Epithelial Barrier Dysfunction During Salmonella Enterica Serovar Typhimurium Colitis. Infect. Immun. 81, 3672-3683. doi: 10.1128/IAI.00854-13

Zeissig, S., Bürgel, N., Günzel, D., Richter, J., Mankertz, J., Wahnschaffe, U., et al. (2007). Changes in Expression and Distribution of Claudin 2, 5 and 8 Lead to Discontinuous Tight Junctions and Barrier Dysfunction in Active Crohn's Disease. Gut 56, 61-72. doi: 10.1136/gut.2006.094375

Zeng, B., Xing, R., Dong, C., and Xing, F. (2020). Commentary: Group 3 Innate Lymphoid Cells Mediate Early Protective Immunity Against Tuberculosis. Front. Immunol. 11, 1925. doi: 10.3389/fimmu.2020.01925

Zhong, G. (2021). Chlamydia Overcomes Multiple Gastrointestinal Barriers to Achieve Long-Lasting Colonization. Trends Microbiol. 29, 1004-1012. doi: 10.1016/j.tim.2021.03.011

Zortel, T., Schmitt-Graeff, A., Kirschnek, S., and Häcker, G. (2018). Apoptosis Modulation in the Immune System Reveals a Role of Neutrophils in Tissue
Damage in a Murine Model of Chlamydial Genital Infection. J. Infect. Dis. 217, 1832-1843. doi: 10.1093/infdis/jiy126

Conflict of Interest: The authors declare that the research was conducted in the absence of any commercial or financial relationships that could be construed as a potential conflict of interest.

Publisher's Note: All claims expressed in this article are solely those of the authors and do not necessarily represent those of their affiliated organizations, or those of the publisher, the editors and the reviewers. Any product that may be evaluated in this article, or claim that may be made by its manufacturer, is not guaranteed or endorsed by the publisher.

Copyright (C) 2021 Korchagina, Koroleva and Tumanov. This is an open-access article distributed under the terms of the Creative Commons Attribution License (CC BY). The use, distribution or reproduction in other forums is permitted, provided the original author(s) and the copyright owner(s) are credited and that the original publication in this journal is cited, in accordance with accepted academic practice. No use, distribution or reproduction is permitted which does not comply with these terms. 